\title{
AN INVESTIGATION OF DIELECTIC LOSSES WITH THE CATHODE RAY TUBE
}

\author{
BY JOHN P. MINTON
}

\section{Abstract of PAPER}

This paper discusses the theory of the cathode ray tube wattmeter and shows how it can be used to determine directly the power factors of insulations. The current and voltage are measured independently so that the dielectric losses in insulation can be calculated. Such measurements can be made up to the breakdown voltage of the material being tested.

The development of the cathode ray tube and its auxiliary apparatus is discussed.

Measurements of dielectric losses, power factors, and currents, for varnished cloths and oil-treated pressboard, are given. The measurements have been made at 60 cycles at different voltages, temperatures, and moisture contents in the case of pressboard. Curves are given showing the losses, power factors and currents plotted against voltage, temperature, and per cent absorbed moisture.

Empirical equations are derived for all the curves. It is shown that watt losses may vary from the 1.32 to the 2.52 power of the voltage. The losses and currents can be expressed by an equation of the form $K_{1}+K_{2} Y^{n}$, where $Y$ may be temperature in deg. cent. or per cent absorbed moisture. The same form of equation holds for the power factors up to about 85 per cent. The equations given show that the exponent $n$ may vary from about four to seven, depending on the conditions of the tests and on the nature of the insulations.

The large and harmful effects of moisture are clearly shown by the results, and the weakening effects due to high temperature are of much importance.

\section{INTRODUCTION}

CAREFUL study of insulating materials is becoming more and more important. Formerly, if an insulating material was not satisfactory, it was discarded and a new one substituted. In this way considerable progress was made. However, as the number of possible insulators became less, it became more evident that it was necessary to study the electrical properties of these with the hope of improving them. Today, this tendency toward a careful study of various dielectrics is quite prominent, and it is certain to become much more noticeable in the near future. Certainly we are now looking: toward improvement in all kinds of insulations, and in seeking 
this improvement, the most careful and thorough investigations cannot be over-emphasized.

Heretofore, the electrical tests made on insulation have largely been voltage tests, capacity and resistance measurements. The voltage tests are important because insulation must be able to withstand continued application of voltage and sudden voltage increases such as occur in transient phenomena. These tests reveal very little about the insulation because either it does or does not withstand them. This is really about all they do tell us, because if the insulation is broken down, no further test can be made on it, and if it is not broken down, we can say nothing regarding its value as compared with other insulation which fails to break down under test. Capacity measurements are only made at low voltages and not at anything like normal operating voltages. Such measurements are important in helping one to select the proper insulation, but no one would decide to use a certain kind of insulation from consideration of capacity measurements only. These measurements do not tell us enough. In the same way resistance measurements do not tell us enough, and indeed it is difficult to say what the resistance of a piece of insulation is except for direct currents, which at the present time are of much less interest to the engineer than alternating currents.

On account of the inadequacy of the three kinds of electrical measurements mentioned on insulation, the measurement of dielectric losses and power factors of insulations becomes of much importance and of great interest. By means of such measurements, one is able to study a piece of insulation up to almost the breakdown point under a variety of conditions and over and over again. He can continue these measurements until the insulation finally breaks down, and will know what is happening within it up to this point. Such measurements will reveal to us more about insulation than all the three tests referred to above. If scientific progress in insulation engineering is to be made, then measurements of dielectric losses, power factors, and currents will prove most valuable in pointing out ways of advance and in keeping us off wrong paths.

In searching the literature, one at once realizes that very few extended researches have been conducted along the line of dielectric losses. The most notable ones have been carried out in England during the past few years by E. H. Rayner, ${ }^{1}$ by C.

1. "High-Voltage Tests and Energy Losses in Insulating Materials" E. H. Rayner, Journal Inst. Elec. Engrs., Vol. 49, pp. 3-89. 1912. 
C. Paterson, E. H. Rayner, and A. Kinnes ${ }^{2}$, and by Fleming and Dyke. ${ }^{3}$ The latter made use of the bridge method, while the two former made use of the electrostatic wattmeter. Both of these methods have the disadvantage of being limited in the voltage at which they can be used, and the electrostatic wattmeter is a very troublesome instrument with which to work. The whole reason why such measurements have not been carried out on a large scale before is because one is confronted with the difficulty of securing instruments which will measure small losses at very high voltages. Prof. Ryan first suggested the use of the cathode ray tube for this purpose and showed ${ }^{4}$ how it could be used by giving a number of examples of measurements made with it. The development of the cyclograph, which is the name given to the cathode ray tube wattmeter, was begun in 1911 at the Pittsfield Laboratory, and has been accomplished, so that it is a satisfactory apparatus to measure dielectric losses up to almost any desired voltage, from very small to large losses, and from low to high frequencies, so long as a continuous alternating potential is available. The cyclograph has been in continuous use in this laboratory during the past two years, and a large amount of valuable information has been gained both on cathode ray tubes and on insulation. The application of the cyclograph to this work, its development, some of the results obtained with it, and a study of dielectric losses made possible by its use, are embodied in this paper. Since the writer has had little assistance from current literature, he cannot hope to say the last word, or even avoid making wrong inferences. The results and information set forth in this paper may be considered as opening up a new avenue for insulation research for both the electrical engineer and the scientist.

At this point the writer acknowledges his appreciation of the kind interest taken in this work and the helpful suggestions of Mr. A. McK. Gifford, in charge of the Pittsfield Laboratory, and $\mathrm{Mr}$. C. R. Blanchard, in whose section of the laboratory the work has been done. $\mathrm{He}$ is also indebted to Mr. W. C. Slade, of this laboratory, for his willingness to do the necessary

2. "Use of the Electrostatic Method for Measuring Power." C. Paterson, E. H. Rayner and A. Kinnes, Journal Inst. Elec. Engrs, July, 1913, pp. 294-360.

3. " Energy Losses at Telephonic Frequencies." Fleming and Dyke, Journal Inst. Elec. Engrs. Vol. 49, p. 323, 1912.

4. A Power Diagram Indicator, Harris J. Ryan, A. I. E. E., Vol. 30, np. 511-535, 1911. 
glass-blowing in order that this work could be made possible. To the other men in the laboratory, who have assisted in this work either by suggestions or otherwise, the writer expresses his gratitude.

\section{Object of the Investigation}

The object of the present investigation was three-fold. First, to show the usefulness of the cathode ray tube in studying the dielectric losses which occur in insulations. Second, to measure dielectric losses, power factors, and currents at different voltages and temperatures in different insulations under various conditions. Third, to obtain a better understanding of the mechanism of dielectric conduction and to obtain empirical laws governing the electrical phenomena occurring in insulation when it is subjected to high voltage stresses. The results which have been attained and the information acquired through this investigation show that this three-fold object has been accomplished. The results of this work will now be given.

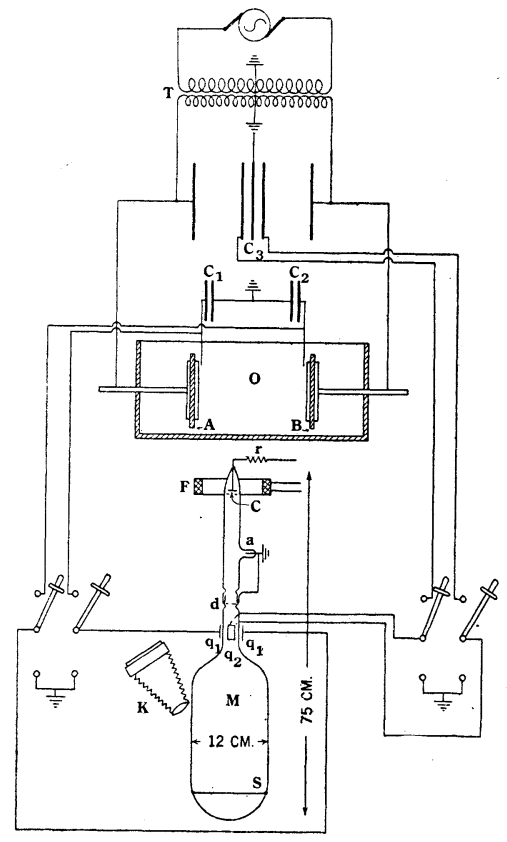

FIG. 1

II. Method of Determining Dielectric Losses

Since the method of determining the dielectric losses with the cyclograph is quite different than that described by Prof. Ryan, ${ }^{5}$ it will be necessary to show how the apparatus is used for this purpose. The cathode ray tube, $M$, is an evacuated glass tube of the dimensions and shape shown in Fig. 1. Under the proper conditions, a direct potential of about 20,000 volts, applied between the cathode $C$ and the grounded anode, $A$, will cause a stream of cathode rays to originate at the cathode and travel at a very high velocity toward the other end. It is necessary to have $C$ the negative terminal because the cathode

5. Loc. cit. (4). 
rays consist of electrons which possess negative charges. A grounded brass diaphragm, $d$, intercepts all these rays with the exception of those which pass through a round hole about $1 / 32$ in. in diameter in this diaphragm. This small pencil or bundle of rays travels to the lower end of the tube where it strikes the fluorescent screen $S$. This fluorescent screen is usually made of calcium tungstate $\left(\mathrm{Ca} \mathrm{WO}_{4}\right)$, or zinc sulphide $(\mathrm{ZnS})$, or some other salt which is strongly fluorescent when subjected to the bombardment of cathode rays. For a fuller discussion of the cathode rays and their properties, the reader is referred to a recent article by the writer ${ }^{6}$. A more complete discussion on the cyclograph will appear in another section, but this will be sufficient to understand the theory of the apparatus.

Theory of the Cyclograph. In order that the fluorescent

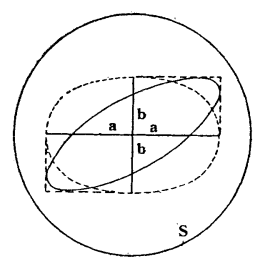

Fig. 2-FIGURES

PRODUCED BY THE Fluorescent Spot on the Sensitive SCREEN $S$ figure on the screen may be symmetrical with respect to the center, it is necessary in this scheme to use two pieces of similar insulation. These two pieces are represented by $A$ and $B$ and placed between the test terminals in the oil-box, $O$, as shown in Fig. 1. Suppose now a high-potential sine wave is applied to these test pieces by means of the transformer $T$, and that it is desired to measure the dielectric loss in them. Fig. 1 shows the diagram of connections to be used. For this purpose, a sine-wave potential, proportional to the voltage across the test terminals in the oil-box is applied to the potential quadrants, $q_{2}, q_{2}$. This potential is obtained from the air potential condenser $C_{3}$, as shown in the diagram. It may be represented by:

$$
e=e_{0} \sin p t
$$

This potential produces the deflection of the cathode ray spot on the fluorescent screen $S$, as shown by $b b$ in Fig. 2 . Since the cathode rays possess no appreciable inertia, it follows that this deflection is directly proportional to $E$, so that

$$
b=k_{0} e_{0} \sin p t
$$

To the current quadrants, $g_{1} q_{1}$, is applied a potential $e_{1}$, proportional to the current passing through the insulation under

6. "Cathode Rays and Their Properties." J. P. Minton, General Electric Review, Vol. 18, pp. 118-125, 1915. 
test in the oil box. This potential is obtained from the air current condensers, $C_{1}$ and $C_{2}$, as shown in Fig. 1 . The voltage across an air condenser is directly proportional to the current passing through it. The current that passes through these condensers is that which passes through the insulation under test, and it may be represented by

$$
i=I_{0} \sin (p t+\theta)
$$

where $\theta$ is the angle of lead of the current over the voltage applied to the test terminals. Since $i$ leads $e_{1}$ by 90 degrees and since $i$ is proportional to $e_{1}$, we have from equation (3):

$$
e_{1}=k_{1} I_{0} \cos (p t+\theta)
$$

This potential $e_{1}$ produces the deflection $a a$ of the cathode ray spot as shown in Fig. 2. The deflection is proportional to $e_{1}$, so that

$$
a=k I_{0} \cos (p t+\theta)
$$

Placing $a=x, b=y$, and $k_{0} e_{0}=k_{2} E_{0}$, we have, rewriting equations (5) and (2),

and

$$
x=k I_{0} \cos (p t+\theta)
$$

When both of these potentials act on the cathode ray stream simultaneously, an ellipse is formed on the screen, $S$, by the fluorescent spot, in Fig. 2. The area of this ellipse is given by

$$
A=\int_{0}^{2 \pi} y d x
$$

Making use of equations (6) and (7), we obtain from equation (8)

$$
A=-k k_{2} E_{0} I_{0} \int_{0}^{2 \pi} \sin p t \sin (p t+\theta) p d t
$$

or

$$
A=-k k_{2} E_{0} I_{0} \int_{0}^{2 \pi}\left(\cos \theta \sin ^{2} p t+\sin \theta \sin p t \cos p t\right) p d t
$$

Integrating and placing in the limits of integration we obtain

$$
A=-\pi k k_{2} E_{0} I_{0} \cos \theta
$$


Placing $-\pi k \quad k_{2}=$ a constant, and replacing the maximum values of $E_{0}$ and $I_{0}$ by their effective values $E$ and $I$, we have

$$
A=K E I \cos \theta
$$

Now, $E=$ the voltage applied to the system, $I=$ current passing through the insulation, and $\cos \theta=$ the power factor of the system. Therefore, the area, $A$, of the ellipse is proportional to the power lost in the insulation and air condensers, $C_{1}$ and $C_{2}$. Since the loss in the air condensers is negligible, we see that the area of the ellipse is proportional to the dielectric loss in the two pieces of insulation under test. This is the same result obtained by Prof. Ryan by a different line of reasoning. However, the use of the cyclograph in this manner would require calibration under various conditions in order to determine the multiplying factors necessary to reduce the area to units of power. Calibrations are not pleasant things to obtain, and, fortunately, they are not at all necessary. These calibrations are avoided by the use of the cyclograph as a power factor meter by measuring the currents and voltages independently. These two latter quantities can be determined without trouble and we shall see that the power factors are easily obtained from photographs taken of the fluorescent figure.

Use of the Cyclograph as a Power Factor Meter. Equation (12) gives the area of the ellipse when the power factor of the circuit (consisting of the two test pieces and air condensers $C_{1}$ and $C_{2}$ ) is equal to $\cos \theta$. If the power factor of the circuit were unity instead of $\cos \theta$, then the area, $A_{0}$, of the ellipse would be equal to $K E I$, and it is represented by the dotted ellipse in Fig. 2. It is evident that

$$
\frac{A}{A_{0}}=\frac{K E I \cos \theta}{K E I}=\cos \theta
$$

$A$ can be obtained by measuring the major $\left(a^{\prime}\right)$ and minor $\left(b^{\prime}\right)$ axes of the actual ellipse formed by the fluorescent spot on the screen, $S_{1} \cdot A_{0}$ can be obtained by measuring $a$ and $b$, Fig. 2 . Hence, $\cos \theta$ can be determined by applying equation (13). This makes it evident that it is advisable to make three exposures for each photograph, one of the ellipse, one of the deflection $a$, and one of the deflection $b$. However, one exposure, that of the ellipse, would be sufficient to determine $\cos \theta$. These photographs are taken at an angle as indicated 
in Fig. 1, but on account of taking the ratio of $A$ to $A_{0}$, no errors are introduced in the values obtained for $\cos \theta$.

Equation (13) gives the value of the power factor of the circuit, but one desires the power factor of the insulation which is being tested. This is obtained from Fig. 3, which is the vector diagram for the circuit consisting of the two test pieces and air condensers $C_{1}$ and $C_{2}$. The voltage across this circuit is represented by $E$, and the current passing through it is represented by $I$ leading $E$ by an angle $\theta . \quad e_{1}$ is the potential drop across the air condenser, and it is at right angles to $I$. $E^{\prime}$ is the voltage drop across the insulation, and $\theta^{\prime}$ is the phase angle between $I$ and $E^{\prime}$. The power factor of the insulation, therefore, is $\cos \theta^{\prime}$, which is the one sought. It can be determined as follows:

$$
\begin{aligned}
& \sin \alpha=\frac{e_{1}}{E^{\prime}} \cos \theta \\
& \cos \theta^{\prime}=\cos (\theta-\alpha)
\end{aligned}
$$

From which it follows that:

$$
\cos \theta^{\prime}=\frac{e_{1}}{E^{\prime}} \sin \theta \cos \theta+\cos \theta \sqrt{1-\frac{e_{1}^{2}}{E^{\prime 2}} \cos ^{2} \theta}
$$

Now, $\frac{e_{1}^{2}}{E^{\prime 2}} \cos ^{2} \theta$ is of such a value that it can be neglected and in doing so, an error not greater than 0.7 per cent will be introduced in the values obtained for $\cos \theta^{\prime}$. Hence equation (14) becomes approximately

$$
\cos \theta^{\prime}=\cos \theta+\frac{e_{1}}{2 E^{\prime}} \sin 2 \theta
$$

Below we shall see how to determine $e_{1}$ and $E^{\prime}$, and from equation (13) we can calculate $\theta$. Hence, by substituting the values for these three quantities in equation (15), we obtain the values for $\cos \theta^{\prime}$, the power factor of the insulation being tested. The value of the correction term in equation (15) is obtained by plotting $\cos \theta$ vs. $\frac{1}{2} \sin 2 \theta$. Then, when we know $\cos \theta$, we can get values for $\frac{1}{2} \sin 2 \theta$ from the curve. Multiplying these values by $e_{1}$ and dividing by $E^{\prime}$, we obtain the corrections. These corrections amount from about 0 to 10 per cent of cos $\theta$, depending on the conditions of the tests. 
Measurement of Current. The current that passes through the insulation also passes through the air condensers $C_{1}$ and $C_{2}$. Under normal conditions, the current passing through any air condenser is given by

$$
I=2 \pi f C e_{1} \times 10^{-6} \text { amperes, }
$$

where $e_{1}=$ potential in volts across the condenser,

$C=$ capacity in mfd. of the condenser,

$f=$ frequency of the applied potential.

So that this equation can be used to obtain the current passing through the insulation.

The voltage, $e_{1}$, across the air condensers has been determined with a 120-volt Kelvin electrostatic voltmeter used either with a shunt or with two auxiliary condensers, one connected on each side of the ground between $C_{1}$ and $C_{2}$ in Fig. 1 . In the first case the voltmeter was calibrated to read directly the

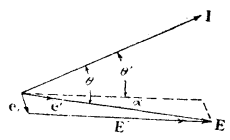

Fig. 3-Vector Diagram FOR TESTING Circuit
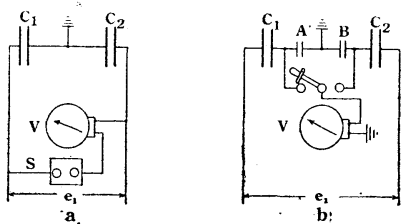

FIG. 4

voltage across the two condensers $C_{1}$ and $C_{2}$. In the second case, the voltmeter was calibrated to read directly the voltage across these two condensers plus the two auxiliary condensers. The second method has proved much more reliable because one terminal and the metallic case of the electrostatic voltmeter can be grounded, and the auxiliary condensers are sufficiently large to permit the 120 -volt Kelvin meter to be connected directly across them. The first scheme is represented in Fig. $4 a$ and the second in $4 b$. In $4 b$, the average of the readings across $A$ and $B$ is taken to represent the value of $e_{1}$ to be used. $e_{1}$ varies from 600 to 3000 volts, depending on the conditions of test. This second method is quite satisfactory, and can always be relied upon to give accurate results. The shunt method is objectionable because it requires a very small capacity for the shunt, and it is affected by disturbing influences, which will not affect the second method in the least. These two auxiliary condensers, $A$ and $B$, have sections of different capacities and 
one section or another can be switched in or out, depending on the amount of current passing. They are made of paraffinetreated bond paper and each occupies a space 10 in. by 8 in. by 2 in., being firmly constructed so as not to undergo any change in capacity. The loss in these paraffine condensers is less than one part in two or three hundred of the total losses, so that they introduce no appreciable error in the results.

The air capacities, $C_{1}$ and $C_{2}$, or these in series with the two auxiliary condensers $A$ and $B$, range from about 0.003 to 0.015 microfarad. This range has been found sufficient for this work on dielectric losses. The frequency of the applied potential is measured without any difficulty. Therefore, the current can be calculated by means of equation (16). The current per sq. $\mathrm{cm}$. can be obtained by dividing the total current by the area of the testing terminals; all the current values given in this paper are in milliamperes per sq. $\mathrm{cm}$. The test terminals used were either 20 or $25.4 \mathrm{~cm}$. in diameter, and results obtained with $10-\mathrm{cm}$ terminals were the same as those obtained with the $25.4-\mathrm{cm}$. ones, so that the edge effect was negligible.

Measurement of Voltage. The voltage, $E$, applied to the test terminals, was obtained by reading the voltage on the low side of the testing transformer, and calculating $E$ by the ratio of transformation. This ratio was $87: 1$, and was accurately determined. The voltage $E^{\prime}$ across the insulation can be calculated from the equation

$$
E^{\prime}=\sqrt{E^{2}+e_{1}^{2}-2 E e_{1} \sin \theta}
$$

This equation can be derived from the geometry of Fig. 3. E, $e_{1}$, and $\theta$ are known, as explained above, so that $E^{\prime}$ can be calculated.

Calculation of Losses. The watts lost in the two pieces of insulation under test are given by the equations:

or

$$
W=E^{\prime} I \cos \theta^{\prime}
$$

$$
W=E I \cos \theta
$$

where the potential and current are in volts and amperes, respectively. Equation (18) is the one that is always used, for it is desired to know both the voltage across the insulation and its power factor. This gives the total watts; watts per cu. $\mathrm{cm}$. can be obtained by dividing the total watts by the actual volume of insulation under test. 
One is likely to imagine that considerable time is required to secure data for one point, that is, data for calculating the power factor, the current, the voltage and the watts. As a matter of fact about 30 seconds are required to make the three exposures for each photograph, and about a minute more is required to obtain all the other necessary readings. We thus see that a considerable amount of data may be taken in a very short time. In about 10 minutes, we can secure data to give curves showing watts vs. voltage, current vs. voltage, and power factor vs. voltage.

An illustration of the cyclograph as it is set up in the small dark house, is shown in Plate CX. Reference will be made to this in the section devoted to the development of the cyclograph, which will now be considered.

\section{Development of the Cyclograph}

A great deal has been written on the cathode ray tube but, regardless of the information given in the literature, it was found necessary to develop the tube practically from the beginning and to study carefully its characteristics. Little assistance has been derived from the literature because the object of this work was to develop tubes for commercial purposes. The tubes, therefore, must be reliable and constant in their operation over a period of several years. Tubes which will fulfill the requirements for this purpose must necessarily be superior to those required perhaps a few times a year. Tubes which are satisfactory to carry out investigations extending over a period of a few days or weeks, would not prove of value for investigations covering a period of several years. The desirability of having tubes ready for use at any time, just as a galvanometer is, has constantly been kept in mind. It is the writer's belief that this has now been accomplished, and tubes which have been used continually during the past two years indicate that reliable ones can be built without much difficulty.

Some of the important observations made in the development of the cyclograph and a comparison of the results obtained with those of other investigators will be given. A more detailed account of this is to be published elsewhere, ${ }^{7}$ and it will not be necessary, therefore, to go into too much detail here. Reference should be made to the above-mentioned article if one desires to go into this subject more fully than given below.

7. General Electric Review, July, 1915. 
Vacuum Characteristics. Attention will first be given to the vacuum characteristics of cathode ray tubes. In the literature on this subject one will find that reference is made to trouble encountered with "hardening" and "softening" effects in these tubes. The "hardening" is an increase and "softening " a decrease of the vacua. These changes may occur either during operation or at other times. Several suggestions ${ }^{8}$ have been made to counteract or eliminate these effects. There are four methods. The first uses an auxiliary side tube made of platinum, or better still palladium, through which gas can enter the tube when the metal is heated for a few seconds at red heat. This method allows a reduction in vacuum but is useless for increasing it. In the second, an auxiliary side tube containing acid sodium carbonate has been employed. This salt liberates a gas when a discharge of electricity takes place through it. Consequently, this auxiliary side tube possesses an electrode, and by passing a discharge between it and the anode the vacuum is reduced. This scheme, therefore, allows only a reduction in vacuum to be obtained. A third method is to have a side tube connected to the main tube through a stop-cock. If the pressure becomes too small, a little gas is admitted from this side tube. Another side tube containing platinum-black, which readily absorbs large quantities of gases, is also connected to the cathode ray tube through a stop-cock. If the pressure becomes too great the platinum-black is allowed to remove a sufficient quantity of gas to give the desired vacuum. The fourth method is to have the cathode ray tube connected continually to an exhausting system. The vacuum can then be adjusted at any time to any desired degree.

Evidently, the first two methods of vacuum regulation are unsatisfactory for commercial work.

The third scheme is not suitable because slight changes in pressure affect the operation of the tubes greatly, and it is diffcult to obtain fine regulation by operating stop-cocks. Such a scheme as this makes the construction of the tubes more complicated.

8. (a) Loc. cit. (4), p. 530.

(b) "Apparate und Verfahren zur Aufnahme und Darstellung von Weckselstromkurven und elektrischen Schwingungen." H. Hausrath; Helios. Fach-Zeitschift fur Elektrotechnik, Zeite 527, 1914.

(c) Fortschnitte auf dem Gebiets der Röntgenstrahlen Bd. 18, Heft 2, 1912, Heinz Bauer. 
PLATE CX.

A. I. E. E.

VOL. XXXIV, 1915

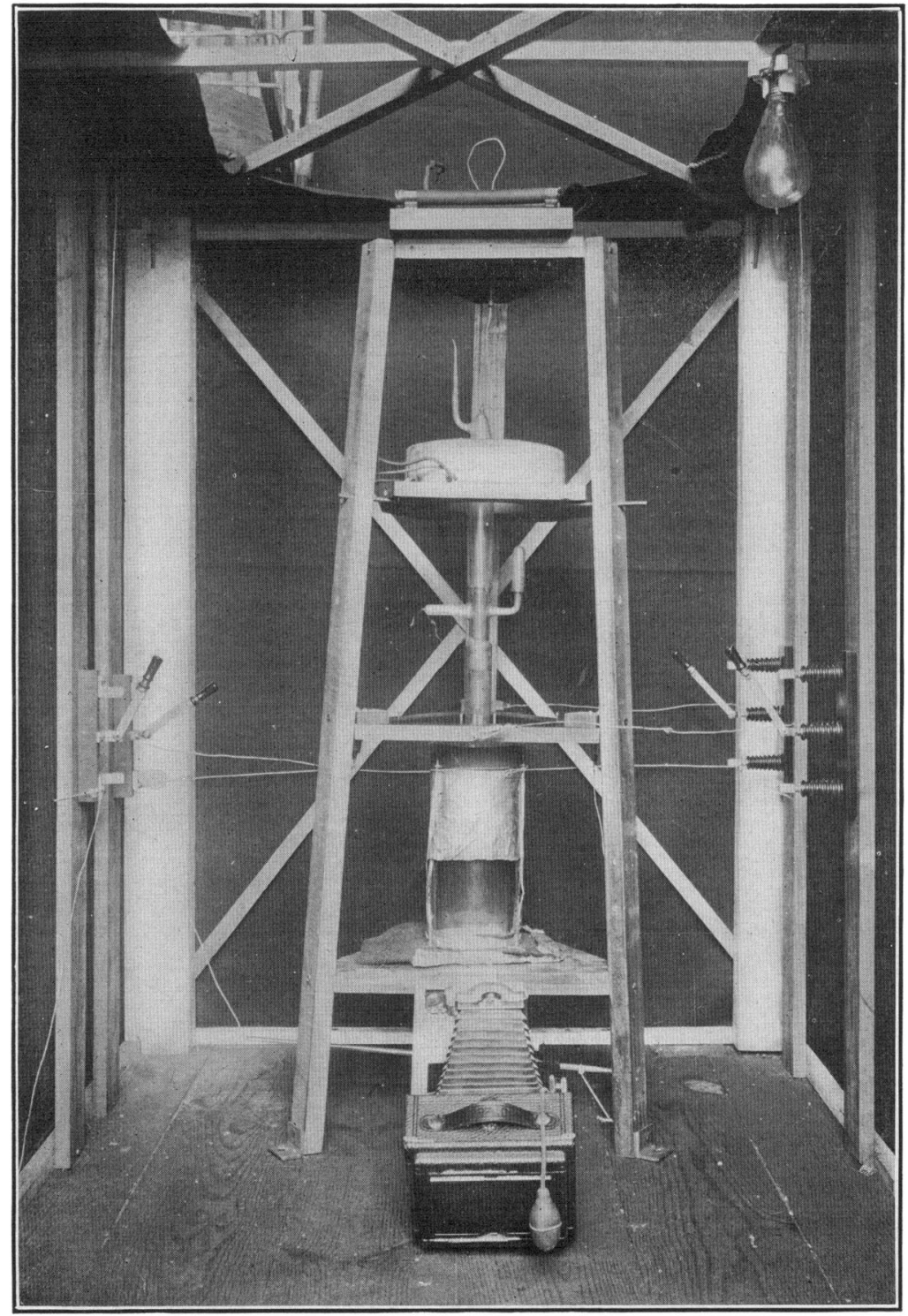

Cyclograph in Small Dark Room

[MINTON] 
Likewise, the fourth method is unsatisfactory for one cannot afford to have suitable vacuum pumps installed where he desires to use the tubes.

These difficulties and objections lead to the belief that if satisfactory tubes were made it would be necessary to have them maintain constant vacua of the desired magnitudes under all ordinary conditions of operation. The development of such tubes was undertaken. It was finally shown that the vacuum " softened " because too much gas was adsorbed on the surface of the electrodes and glass walls. After the tubes had been operating for a few minutes, the vacua would rapidly decrease and would be entirely unsatisfactory for use. If too much adsorbed gas was liberated, then the tubes "hardened" because some of the gas was withdrawn from the interior of the tubes and adsorbed on the walls and electrodes. It was found, however, that if the tubes were exhausted three or four hours at perhaps $350 \mathrm{deg}$. cent. sufficient adsorbed gases were liberated from the glass walls and electrodes to maintain constant vacua over long periods of time. One tube has now maintained a constant vacuum for almost two years and there is no indication that it will not maintain this vacuum for a number of years, although it is used almost daily. Not one exception to this rule has been found. Some tubes have been operated about ten hours continuously with such strong rays that one could not touch the glass around the cathodes without receiving severe burns. Even in these most extreme cases, the vacua remained constant. It may be said, therefore, that when tubes are exhausted in this manner they will maintain constant vacua, thus requiring no vacuum regulators of any kind. This is not only a great improvement over tubes of other makes, but it insures reliable ones for experimental purposes.

It should be stated that one should be careful not to allow the pressure to increase to atmospheric value when once the tubes have been exhausted at a high temperature. If this should occur, it may be necessary to re-exhaust them at a high temperature in order to eliminate possible vacuum troubles. This has been found necessary several times.

Electrostatic Charges on Glass Surrounding Cathodes. Another difficulty was encountered in the development of cathode ray tubes. This difficulty was due to electrostatic charges which accumulated on the glass surrounding the aluminium cathodes. These charges were of a positive sign and, since the cathodes 
were negative, it meant that discharges would occur between the cathodes and glass as soon as the potential differences reached a sufficient magnitude to cause the discharges. Such dicharges always caused the cathode ray streams to be unsteady, and frequently resulted in flash-overs within the tubes between the cathodes and anodes. The flash-overs were prevented by the use of high resistances (perhaps 100,000 ohms each), such as high-resistance lightning arrester rods, in the cathode leads. These resistances should connect immediately to the cathode terminals as shown by $r$ in Fig. 1. These resistances not only prevent flash-overs, but they also cause the tubes to operate much more steadily. They do not, however, prevent discharges from occurring between the cathodes and the glass surrounding them. A number of investigators have encountered this difficulty and have tried to eliminate it in various ways. To avoid this trouble Dr. Zenneck ${ }^{9}$ surrounded the cathodes with glass formed into small cups as illustrated in Fig. 5A. Roschansky ${ }^{10}$, for the same purpose, placed behind the cathodes metallic screens and filled the space between these and the glass with ruffled tin-foil leaves. This scheme is illustrated in Fig. 5B., where $S$ is the metallic screen and $L$ the ruffled tinfoil leaves. Grundelach, in his tube, made the cross-section of the cathode almost large enough to fill the tube, as illustrated in Fig. 5c.

A tube of Dr. Zenneck's design made in Germany was tried, but the glass " hinter-
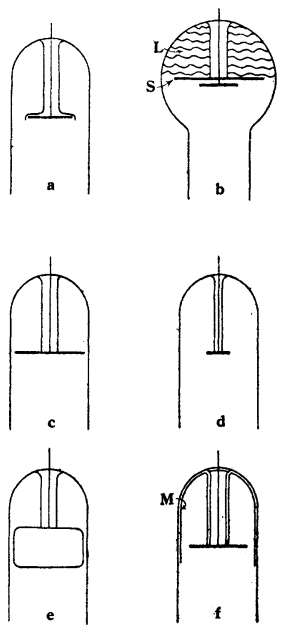

FIG. 5 kleidung" did not prevent static discharges between it and the cathode. It did, however, prevent them from occurring between the cathode and the glass wall of the tube. The discharges between the cathode and the glass "hinterkleidung " caused unsteady cathode rays. The size, shape, and position of the cathodes and the kind of glass used have a great deal to do with the accumulation of these static charges and with the operation of the tubes. For example, cathodes of the shape shown in Fig. 5D give much trouble on account of the frequency of static discharges between them and the glass. Cathodes of the form shown in Fig. 5E are the most satisfactory; those il-

9. Zenneck-Weid. Ann. 69, p. 842, 1899.

10. Roschansky, Ann. d. Phys. 36, p. 281, 1911. 
lustrated in Fig. 5c are quite satisfactory. It was found, however, that none of the schemes, with the exception of Roschansky's, which has not been tried, would prevent the trouble due to static discharges.

It was evident, therefore, that this trouble must be avoided by other means. It was noticed that tubes whose vacua " softened " during operation never gave any trouble due to these electrostatic charges. Tubes which have been exhausted several hours at a high temperature in order to eliminate vacuum changes are always unsatisfactory because of the difficulty with the charges. Since the adsorbed gases are liberated from the glass during exhaustion at about 350 deg. cent., it would seem that the reason the charges accumulate during operation of the tubes is on account of a film of gas on the glass being necessary for conducting away the charges. If a sufficient film is present on the glass, the charges are conducted to the cathodes and there newtralized, but if the film is removed, then the charges accumulate until they are neutralized by discharges between the cathodes and the glass. This phenomenon occurred with any form of cathode and with any kind of glass. It should not occur, say, in a tube whose cathode end is constructed as shown in Fig. 5F, where $M$ is a metallic screen. This construction, however, was not necessary, for the following scheme of exhaustion was found to eliminate all trouble of this kind. The idea was to remove a sufficient amount of the film of gas by exhausting the tubes at a high temperature, in order to allow a constant vacuum to be maintained and still leave on enough of the film to conduct away the charges which collect on the glass surfaces. After some experimenting, it was found that if the tubes were exhausted at about $350 \mathrm{deg}$. cent. for perhaps a half-hour, the vacua would remain constant during several hours of continuous heavy operation, and no trouble would be experienced on account of charges on the glass surrounding the cathodes. Exhaustion at a high temperature for this time was sufficient to avoid vacuum changes over long periods. This method of exhaustion has been tried on a number of experimental tubes and found to be satisfactory. One reason, therefore, why this trouble has been encountered so much is because the tubes have been exhausted for too long periods ${ }^{11}$ at high temperature in order to avoid vacuum changes.

Regarding the kind of glass which will prove most satisfactory, it may be said that soft sodium glass has given less trouble with

11. Loc. cit. (8) (b), p. 527 . 
these static discharges than any other glass tried. This glass is also easy to work, and it is easier to adjust the time of exhausting at a high temperature to eliminate static charges and maintain a constant vacuum with this glass than with other kinds of glass tried.

Auxiliary Apparatus. Under auxiliary apparatus are classed the deflecting quadrants, means of exciting the cathode ray tube, the focusing coil, and the potential and current condensers. These will be briefly discussed in the order given.

(a) The Deflecting Quadrants. The method used to deflect the cathode rays is an electrostatic one, and for various reasons practically all investigators have the deflecting quadrants placed within the tubes instead of outside as shown in Fig. 1 . If the deflections are proportional to the voltage impressed on the quadrants, then it is not at all necessary to place them within the tubes. These tubes have been in use during the past three years in the laboratory and it has never been found necessary to have the quadrants inside the tubes. With the single exception, described below, this law has always been obeyed. Since, therefore, these quadrants can be placed outside the tubes, it greatly simplifies their construction. It also permits easy adjustment of the magnitude of the deflections, a thing which is highly desirable in this work. The quadrants are made of pieces of brass about 0.5 in. by $1.0 \mathrm{in}$. and they must be supported by a material which has a very high insulation resistance and one which does not change due to surface leakage or otherwise. The reason for this is that the potential condenser is of small capacity and a small leakage current will cause the results to be considerably in error. It has been found that hard rubber serves this purpose nicely and accurate results can always be obtained with it. The hard rubber is never exposed to sunlight which causes its surface to deteriorate. The switches connecting the leads to the potential quadrants should have hard-rubber bases with considerable leakage surface. Since the current condensers are so much larger than the potential one, it is not necessary to have such highly insulated switches. This does not mean, however, that care should not be exercised with their construction.

One other important point in connection with the quadrants should be mentioned. During damp weather, moisture will deposit on the surface of glass. Formerly, this always happened with the cathode ray tubes, and sometimes it was im. 
possible even to deflect the rays because the deposited moisture acted just like a metallic shield for the rays. In this condition reliable results could not be obtained, and, indeed, one was never certain of the results. It was necessary to make the tubes completely non-hydroscopic in the neighborhood of the quadrants in order to insure satisfactory results. Cellulose nitrate has been used for this purpose and it has been found quite satisfactory. This substance is made into a paste with ether and painted on the tubes with a brush over a distance of a few inches on either side of the quadrants. The paste soon dries, leaving a layer of cellulose nitrate about $0.3 \mathrm{~mm}$. thick over the surface of the glass. Since this procedure has been followed no inconsistencies of any kind have been observed, and this procedure is imperative for accurate results.

(b) Excitation of the Tubes. There are several methods which can be used for exciting the cathode ray tube. One method is the use of a high-potential storage battery consisting of about 20,000 cells. The space occupied by this number of cells, each being about one inch by one inch by five inches in size, would be too large to make the use of the high-potential storage battery of any commercial value. There are a number of other evident objections to the employment of the storage battery. The electrolytic rectifier was not satisfactory because it gave a fluctuating d-c. potential. The static machine has been used largely for operating the tubes, especially in England and Germany. This machine, however, was not found to produce a sufficiently constant potential, especially during damp weather, to maintain steady cathode rays as required for the cyclograph. The kenotron, ${ }^{12}$ which has been developed by the Research Laboratory at Schenectady, has been tried as a means of exciting the tubes. This apparatus has not been used extensively, but it produces a steady cathode ray stream, and there is no apparent reason why it could not be used to good advantage in this work. It is quite simple in its construction and operation.

The mechanical rectifier has been largely used in connection with the cyclograph for producing the cathode rays. The form of commutator used and the diagram of connections are illustrated in Fig. 6. The commutator, $R$, is connected to the

12. "A New Device for Rectifying High-Tension A'ternating Currents-the Kenotron." Saul Dushman, General Electric Review, Vol. 18, pp. 156-167, March, 1915. 
shaft of a small four-pole motor-generator set which supplies the low tension of the 60 cycle transformer, $T$. The commutator can be adjusted so that it will rectify the peaks of the a-c. wave. The rectified direct potential charges the condenser, $C$, to a voltage corresponding to the adjustment of the commutator. The condenser, $C$, supplies the direct potential to operate the tubes. The energy consumed by the tubes is so small that they operate quite steadily, thus showing that the potential of the condenser remains practically constant. This condenser consists of four ordinary Leyden jars connected in parallel. The present commutator will operate up to about 30,000 volts, which is all that is required for the tubes. Care must be taken to have good contacts between the brushes and the segments, because poor contacts in the system supplying the direct potential for the tubes cause unsteady cathode rays. One essential for good contacts is to adjust the brushes so that they are almost tangent to the commutator. Fibre gives sufficient strength and insulation for the commutator. The only metal parts are the segments, brushes, and connecting strips, $a$ and $b$.

(c) Focusing Coil. Prof. Ryan ${ }^{13}$ and Mr. Rankin ${ }^{14}$ have said much

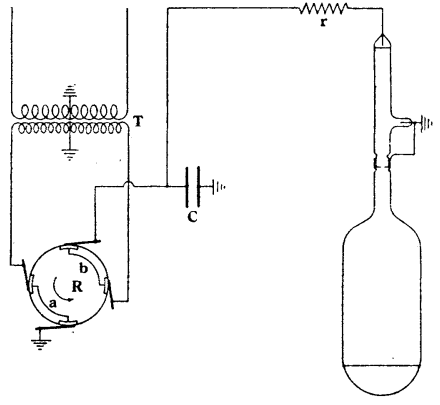

FIG. 6 concerning the focusing coil, $F$ (Fig. 1), and its use in concentrating and increasing the brightness of the fluorescent lines on the screen. It will not be necessary, therefore, to discuss this apparatus and its action for it would simply be repeating what they have already said. It will be well to emphasize, however, that it is necessary for the axis of the focusing coil and tube to exactly coincide. If this condition is not fulfilled, then the figures on the screen will not be symmetrically located with respect to the center. Neither the area of an ellipse nor the magnitude of the deflections is changed by moving them over the screen with the focusing coil, so that no error is introduced into the results by not having the above conditions carried out, but one who is not familiar with the character-

13. Loc. cit. (4), p. 527-528.

14. Rankin "Use of a Magnetic Field with the Ryan Cathode Ray Oscillograph", Phys. Review, Vol. 21, pp. 399-406, 1905. 
istics of the tubes might be inclined to look with skepticism upon the results.

It has been stated that only the brightness of the fluorescent spot on the screen and not its size is affected by the use of the focusing coil. The observations, which have been made in connection with the development of the cyclograph, do not bear out this statement. When the coil is placed just above the plane of the quadrants, the spot and the lines are not only magnified in brightness for the same applied potential, but they are also finer and much more sharply defined. This would be the proper place for the focusing coil if it were not for the effect of the magnetic field superimposed on the electrostatic field. The focusing coil is always placed so that its plane coincides with that of the cathode.

(d) Potential and Current Condensers. The potential condenser consists of hollow metallic tubes with their ends closed by semi-spherical caps. About six of these are joined together with metallic rods and supported from the ceiling with insulators. Two such plates constitute the outer plates of the potential condenser, $C_{3}$, shown in Fig. 1 . The inner plates are about $2 \frac{1}{2} \mathrm{ft}$. by $2 \mathrm{ft}$. by $\frac{1}{8}$ in. The middle one is grounded and supported firmly, while the two adjacent ones on either side are supported from the ceiling with hard rubber. These hard rubber supports are necessary for the reason stated in the section on "Deflecting Quadrants." It is essential to have air as the dielectric for the potential condenser because an error would be introduced into the results if the phase angle of it were not 90 degrees. In the theoretical discussion of the cyclograph, it was assumed that the phase angle was 90 degrees.

The current condensers should have air for the dielectric, for at least four reasons. First, if these condensers are broken down, as they are when the test pieces are broken down, then those with air dielectrics are self-restoring. Those with other dielectrics might be broken down and cause one considerable trouble in repairing them. Second, it is necessary to have current condensers which never change in capacity. The air condensers used have not changed more than one per cent in capacity during the past two and a half years. Condensers with other dielectrics would likely cause errors in the results due to capacity changes. Third, if condensers with dielectrics other than air are used, then it is necessary to correct the results for the losses in them. It is better to eliminate these 
losses rather than correct for them. Fourth, in the formulas used for calculating the current and power factor of the insulation, a perfect condenser was assumed. These current condensers are constructed so as to have the minimum current possible pass through the supporting frames.

Peculiarities of the Tubes. At this stage it will be well to refer to several points to which attention should be given in order to insure steady operation of the tubes. The first is that care must be taken to eliminate the disturbing effects due to stray magnetic and electric fields. The cathode ray stream should be actuated only by the field applied to the quadrants. Now, the tubes are operated at about 15,000 to 25,000 volts so that a very strong field exists around the cathode lead. This field has caused much unsteadiness in the cathode rays and has given much trouble in taking current readings with the "static voltmeter and condenser shunt method." For this reason the cathode leads should be small, well insulated, lead-covered cables, the sheath being grounded. These cables act as part of the condensers used to supply direct potential for the tubes. So that the resistance, $r$, must be placed as shown in Fig. 6. If it were placed between the condenser and the lead rather than between the lead and cathode, then the tube would be unsteady. In order to completely shield the rays and the leads connected to the quadrants from this field, it is necessary to have a thin metallic hood of some sort extending down almost to the quadrants and up to the cathode lead. The resistance, $r$, is then placed within this hood. This precaution prevents the "jumping" of the figures on the screen due to the field around the cathode lead. It is well to have metallic cylinders over the large part of the tubes as shown in Plate CX. The hole which is seen in the cylinder is for the purpose of allowing photographs to be taken. Such a procedure as this will eliminate much unsteadiness of the rays and prevent the figures on the screen from "jumping." This sort of trouble appears to have been encountered before ${ }^{15}$ but apparently it was not eliminated.

Prof. Ryan found it necessary ${ }^{16}$ to cover the surface of the tubes from the anodes extending past the cathodes with a thick paraffine jacket to avoid irregularity in the cathode ray streams due to corona forming on the cathode leads where

15. Loc. cit. (8) (b), p. 528.

16. Loc. cit. (4), p. 529-530. 
they enter the glass. This corona formation has been observed frequently, but after the cause of unsteadiness mentioned above was eliminated, no irregularity of the cathode ray streams was observed due to this corona formation. It is not necessary, therefore, to provide the tubes with insulating jackets around the cathodes.

Another peculiarity noticed was that when high voltages (3000 or 4000) were applied to the quadrants (due to large losses in the insulation) small areas were obtained when the separate deflections $(a$ and $b$ ) were being photographed. These could not be due to a potential applied to the opposite set of quadrants because they were grounded while the photographs of the other deflections were being taken. These areas were due to fields set up between the leads connected to the upper portions of the switches (see Fig. 1). Leads connected to each pair of quadrants came down on opposite sides of the tube and about 12 in. apart. After the wires of each pair of leads were brought down together and connected to the quadrants no further trouble was experienced from this source. These areas were quite noticeable because the potential and current were almost in phase with each other; this condition may be obtained in insulation, as we shall soon see.

In regard to the salt used for the fluorescent screen, it may be said that calcium tungstate $\left(\mathrm{CaWO}_{4}\right)$ and a zinc sulphide $(\mathrm{ZnS})$ are the most strongly fluorescent salts when acted upon by cathode rays. The former salt is more strongly fluorescent for the weaker rays, while for very strong rays the latter salt is the more strongly fluorescent. Both of these substances, however, will be found useful in making the screens.

Considerable space has now been devoted to the theory of the cyclograph and its development. The remaining portion of the paper will be devoted to a study of dielectric losses and other electrical properties of insulation, such a study being made possible by the development of the cyclograph for this work. The results of some of the tests will first be given and a discussion of them will follow.

\section{Experimental Results}

In section II it has been shown how the dielectric loss, power factor, and current for a piece of insulation are determined. (See equations 18, 16, and 15). These quantities have been determined for a number of different insulating materials 
and have been plotted against the applied voltage, the temperature, and per cent absorbed moisture in the case of paper. Since a very large amount of data on insulation has been taken with the cyclograph during the past three years, it will be possible to incorporate only a small portion of it, in this paper. A sufficient amount of it, however, will be given in the form of curves to enable one to obtain a general idea of what is taking place within a piece of insulation when it is subjected to a high voltage stress under various conditions. These curves "will also give one a knowledge of the magnitude of the quantities involved. Section $V$, contains a closer study of these experimental results and empirical equations are given to represent the results mathematically.

All the tests embodied in this paper have been made at 60 cycles with a generator which produces very nearly a sine wave. The tests were made in good transformer oil to avoid corona and the brass test terminals were either $20 \mathrm{~cm}$. or 25.4 $\mathrm{cm}$. in diameter and $0.5 \mathrm{~cm}$. thick. They were square-edged and arranged so that they could be clamped into position after good contact was obtained.

The original data from which the results were calculated need not be given here. The calculated data, however, are given in the form of curves. The tables from which the curves were plotted are omitted for the sake of brevity. For the purpose of illustrating how the original data were taken and the results calculated, there are given below two tables on oiltreated pressboard, sample No. 2, the results on which are given in a later section and shown graphically in Figs. 19, 20 and 21. It should be stated that the results given in this paper were obtained from data taken for other purposes. For this reason it was necessary, in the case of varnished cloths and in the case of the effect of moisture in pressboard, to take the plotted points off of other curves. In the case of all the other results incorporated in this paper the points represent actual data taken. It should also be stated that some of the units used were English while the others were metric. It is customary in this country to express voltages in volts per mil and thickness in inches. If the metric units had been used it would have been necessary to change them in the English units for comparative purposes. In order to avoid this the English units were used in these cases. In all other cases the metric units were used because it is much better to start think- 
ing in metric rather in English units when there is no standard already established.

\section{ORIGINAL DATA}

Date: 12-14-14.

Generator: sine wave, No. 1080 .

Test terminals: $20 \mathrm{~cm}$. square edged.

Frequency: 60.5 cycles.

Temperature: $60.0 \mathrm{deg}$. cent.

Volts on tube: 21,500 .

Focusing coil: 1.5 amps.

Exposure: Ellipses, each $10 \mathrm{sec}$. Cross lines, each $5 \mathrm{sec}$.

Material: 3/32-in. oil-treated pressboard.

Sample: Two sheets, A and B (see Fig. 1).

Average thickness of sample: $(0.470 \mathrm{~cm}$.) $0.185 \mathrm{in}$.

Total volume under test: $147.7 \mathrm{cu} . \mathrm{cm}$.

\begin{tabular}{|c|c|c|c|c|c|}
\hline \multirow{2}{*}{$\begin{array}{l}\text { Photo } \\
\text { No. }\end{array}$} & \multirow{2}{*}{$\begin{array}{l}\text { Gen. } \\
\text { volts }\end{array}$} & \multicolumn{3}{|c|}{$\begin{array}{l}\text { Volts on paraffine } \\
\text { condenser (Fig. } 4 \text { в) }\end{array}$} & \multirow{2}{*}{$\begin{array}{l}\text { Combination of } \\
\text { air condensers }\end{array}$} \\
\hline & & A & $\mathrm{B}$ & Section & \\
\hline 1 & 141. & 49.3 & 54.2 & 2 & $1,2,3,4$ series \\
\hline 2 & 234 & 78.5 & 87.5 & 2 & $"$ \\
\hline 3 & 361 & 52.0 & 53.5 & 3 & $"$ \\
\hline 4 & 460 & 69.5 & 72.0 & 3 & 1,2 \\
\hline 5 & 552. & 82.5 & 86.3 & 3 & “ \\
\hline 6 & 458 & 69.0 & 71.8 & 3 & 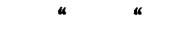 \\
\hline
\end{tabular}

In the table below one will find the calculated results of the above table. The following explanatory remarks apply to this table: $a$ and $b$ are the horizontal and vertical semi-axes, respectively, of the photographs; $a^{\prime}$ and $b^{\prime}$ are the major and minor semi-axes of the ellipses, respectively. $\operatorname{Cos} \theta$ is the power factor of the circuit, while $\cos \theta^{\prime}$ is that of the insulation. The former is equal to $\frac{a^{\prime} b^{\prime}}{a b}$, while the latter is given by equation (15). By means of calibration curves the readings in columns $A$ and $B$ of the above table give the voltage $e_{1}$, see Fig. 4B. The averages of $A$ and $B$, which are always nearly equal, are given in the table below. These average values are used to determine $I$, also given in the following table. $I$ is calculated by means of equation (16). This equation yields the following equations for the various combinations of condensers used: $I_{1}=0.0000186 f e_{1}$, milliamperes, for first combination in the above table; $I_{2}=0.0000197 f e_{1}$, milliamperes, for the second combinations; $I_{3}=0.0000439 f e_{1}$, milliamperes, for the third combination; $f$ is the frequency. The 
equations give the total current passing through the insulation; the current per sq. cm. is obtained by dividing by $314 \mathrm{sq} . \mathrm{cm}$., the area of test terminals. The current values are given in milliamperes per sq. cm. $E$, in $\mathrm{kv}$., is obtained from the generator volts by multiplying by $87.0 \pm 1$ per cent, the ratio of transformation of the testing transformer. $E^{\prime}$, in $\mathrm{kv}$., is calculated by means of equation (17). The volts per mil (V.P. M.) are obtained by dividing $E^{\prime}$ by the total thickness. The total watts are calculated by means of equation (18); dividing by the volume of the insulation, one obtains the watts per cu. $\mathrm{cm}$. In this way the following results were calculated from the above table:

RESULTS CALCULATED.

\begin{tabular}{|c|c|c|c|c|c|c|c|c|c|c|c|c|}
\hline $\begin{array}{c}\text { Photo } \\
\text { No. }\end{array}$ & $\begin{array}{c}a \\
\mathrm{~cm} .\end{array}$ & $\begin{array}{c}b \\
\mathrm{~cm} .\end{array}$ & $\begin{array}{c}a^{\prime} \\
\mathrm{cm} .\end{array}$ & $\begin{array}{c}b^{\prime} \\
\mathrm{cm} .\end{array}$ & $\begin{array}{c}\text { Cos } \\
\text { per } \\
\text { cent }\end{array}$ & $\begin{array}{c}\text { Cos } \\
\theta^{\prime} \\
\text { per } \\
\text { cent }\end{array}$ & $\begin{array}{c}\text { Ave. } \\
\text { cond. } \\
\text { volts }\end{array}$ & $\begin{array}{c}I \text { (m.a. } \\
\text { sq. } \\
\mathrm{cm} .\end{array}$ & $\begin{array}{c}E \\
\mathrm{kv} .\end{array}$ & $\begin{array}{c}E^{\prime} \\
\mathrm{kv} .\end{array}$ & $\begin{array}{c}W \\
\text { C. C. }\end{array}$ & V.P.M \\
\hline & & & & & & & & & & & & \\
1 & 1.13 & 0.55 & 1.28 & 0.050 & 10.3 & 11.3 & 1055 & 0.00379 & 12.3 & 11.2 & 0.0101 & 60. \\
2 & 1.77 & 0.85 & 2.00 & 0.058 & 7.7 & 8.4 & 1685 & 0.00605 & 20.3 & 18.5 & 0.0199 & 100. \\
3 & 2.49 & 1.28 & 2.85 & 0.065 & 5.8 & 6.3 & 2440 & 0.00930 & 31.4 & 28.9 & 0.0359 & 156. \\
4 & 1.55 & 1.60 & 2.13 & 0.060 & 5.1 & 5.3 & 1465 & 0.0124 & 40.0 & 38.5 & 0.0537 & 208. \\
5 & 1.83 & 1.52 & 2.43 & 0.050 & 4.4 & 4.6 & 1745 & 0.0148 & 48.0 & 46.2 & 0.0667 & 249. \\
6 & 1.54 & 1.30 & 2.05 & 0.047 & 4.8 & 5.0 & 1455 & 0.0123 & 39.8 & 38.3 & 0.0502 & 207. \\
\hline
\end{tabular}

As a further means of illustrating how the results are obtained there are given in Plate CXI reproductions of a series of six photographs taken on a sample of varnished cloth at 200 volts per mil. and at various temperatures. These illustrations show that the figures on the fluorescent screen are very steady and well defined. From these illustrations the power factors $(\cos \theta)$ are determined. The following table gives the measurements made on the negatives. The plates used were the American Lumiere sigma.

\begin{tabular}{|c|c|c|c|c|c|c|c|}
\hline $\begin{array}{c}\text { Photo } \\
\text { No. }\end{array}$ & $\begin{array}{c}a \\
\mathrm{~cm} .\end{array}$ & $\begin{array}{c}b \\
\mathrm{~cm} .\end{array}$ & $\begin{array}{c}a^{\prime} \\
\mathrm{cm} .\end{array}$ & $\begin{array}{c}b^{\prime} \\
\mathrm{cm} .\end{array}$ & $\begin{array}{c}\text { Cos } \\
\text { per cent }\end{array}$ & $\begin{array}{c}\text { Cos } \\
\theta^{\prime} \\
\text { per cent }\end{array}$ & $\begin{array}{c}\text { Temp. } \\
\text { deg. cent. }\end{array}$ \\
\hline & & & & & & & \\
1 & 2.70 & 0.85 & 2.91 & 0.045 & 5.7 & 6.3 & 30.0 \\
2 & 2.79 & 0.85 & 3.05 & 0.055 & 7.1 & 7.9 & 71.0 \\
3 & 2.83 & 0.87 & 3.12 & 0.102 & 12.9 & 14.4 & 99.5 \\
4 & 2.90 & 0.87 & 3.17 & 0.187 & 23.5 & 26.2 & 115.0 \\
5 & 1.55 & 0.85 & 1.83 & 0.290 & 40.3 & 42.2 & 130.0 \\
6 & 1.93 & 0.88 & 2.15 & 0.515 & 65.2 & 68.6 & 145.0 \\
\hline
\end{tabular}



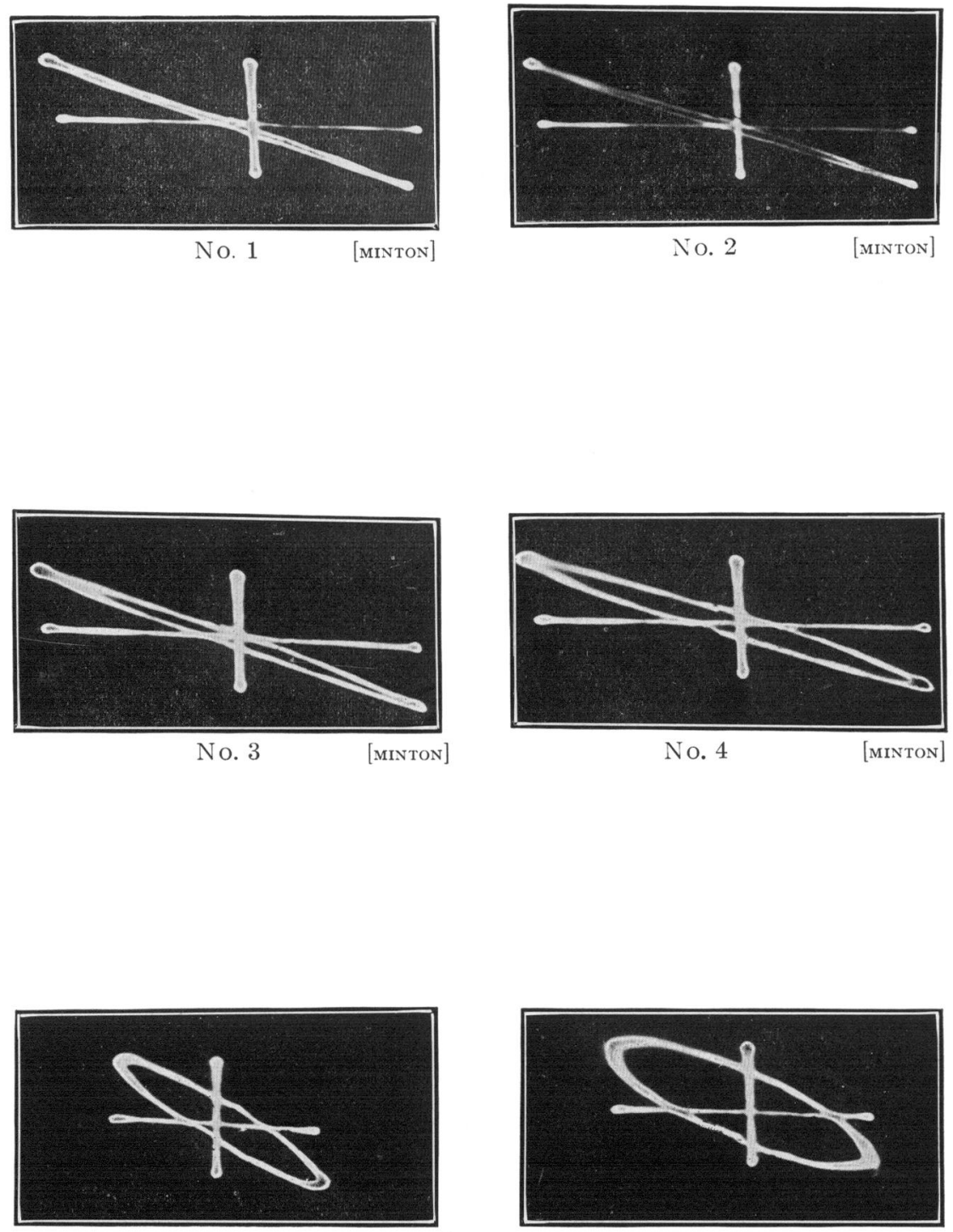

No. 5

[MINTON]

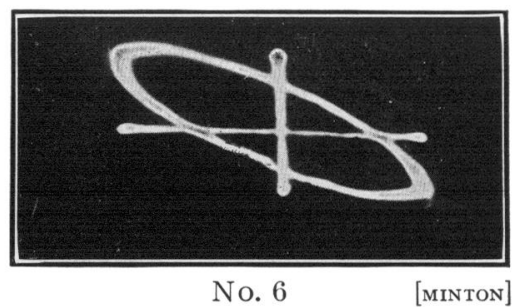


A. Varnished Cloths. A large number of tests have been made on various kinds of varnished cloths. The different test samples were about $30 \mathrm{~cm}$. square, and were built up of separate sheets of the same size to the required thickness. Ordinarily, each of the test pieces, $A$ and $B$, (see Fig. 1) consisted of four or five sheets of varnished cloth assembled under oil, or bound together by thin oil-films, and placed between the test terminals in the oil box. Either method of assembly will yield the same results, as long as good contact is maintained between

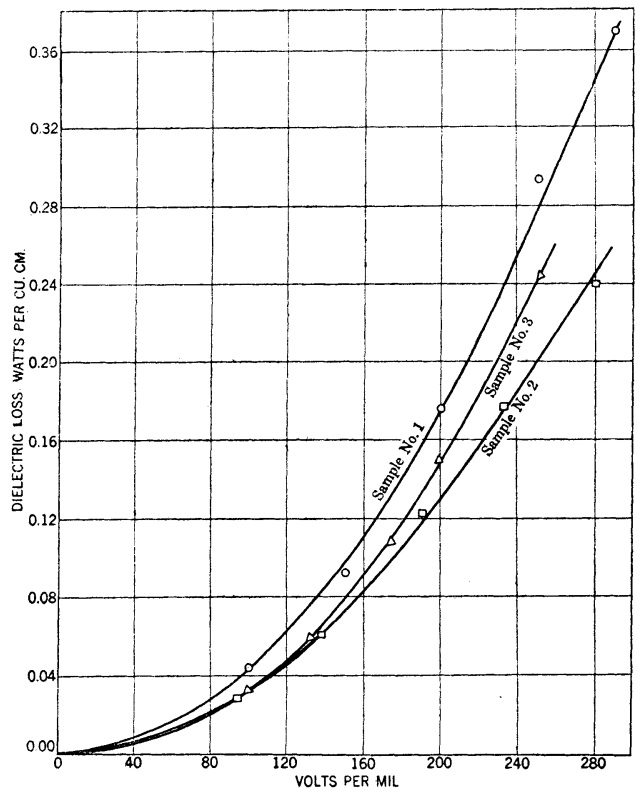

Fig. 7-Twelve-Mil Black Varnished Cloths

Comparative curves showing dielectric loss vs. volts per mil for three different kinds at 100 deg. cent. 60 cycles-sine wave-total thickness: $1-0.1214$ in.; $2-0.1245$ in.; $3-0.1093$ in.

the terminals and test pieces. Tests made on samples ranging from four to twelve sheets also yield the same results.

In Figs. 7 to 12, inclusive, are illustrated some of the results taken on various kinds of varnished cloths. It is seen that the current values in Fig. 9 fall nicely on the lines, but in Fig. 10 quite the contrary condition is noticed. No doubt a large part of this inconsistency is due to the initial condition of the material and to the effect of temperature in producing definite changes in it. Changes of this nature have been noted by 
other observers. ${ }^{17}$ For sample No. 1, it is seen that the losses at $138 \mathrm{deg}$. cent. are forty-five times as great as they are at $25 \mathrm{deg}$. cent. and for sample No. 2, the ratio is twenty-five to one. All the curves shown in Figs. 7 to 12 , inclusive, are consistent in showing that No. 1, No. 3 and No. 2 represent the order in which the samples should be placed, as far as representing their insulating value is concerned.

It will be interesting to compare these results on varnished cloths with those on some others. In one instance, with

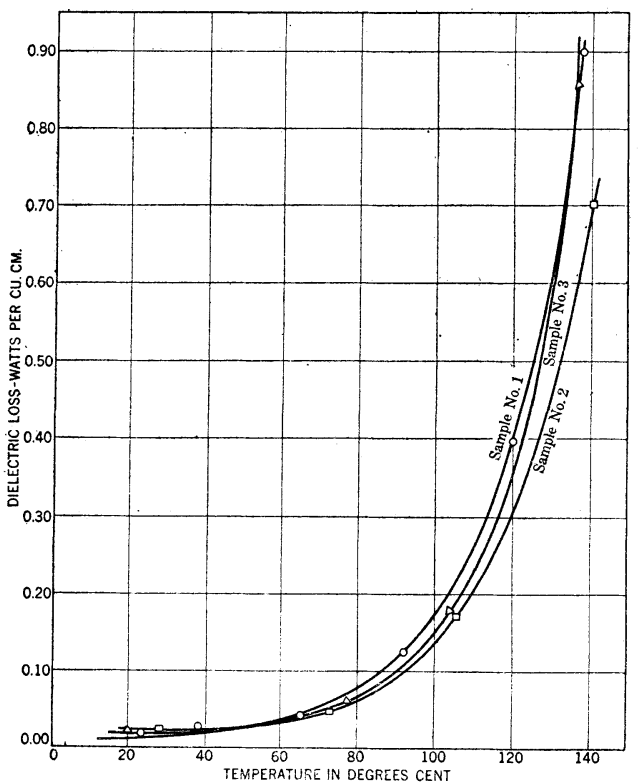

Fig. 8-Twelve-Mil Black Varnished Cloths

Comparative curves showing dielectric loss vs. temperature for three different kinds at 200 volts per mil-60 cycles-sine wave-total thickness: $1-0.1214$ in.;2-0.1245 in.; $3-0.1093$ in.

another varnished cloth at about 200 volts per mil and $100 \mathrm{deg}$. cent., the watts per cu. $\mathrm{cm}$. were about 4.0 , the per cent power factor 98 , and the milliamperes per sq. cm. about 0.050 . Comparing these values with those given in Figs. 7 to 12 , inclusive, one will note the following points: watts per $\mathrm{cu}$. $\mathrm{cm}$. at 200 volts per mil and $100 \mathrm{deg}$. cent. are about twenty-three times as great for the above cloth as they are for sample No. 1; the current value is about five times as great and the power factor

17. Loc. cit. (3), p. 365. 


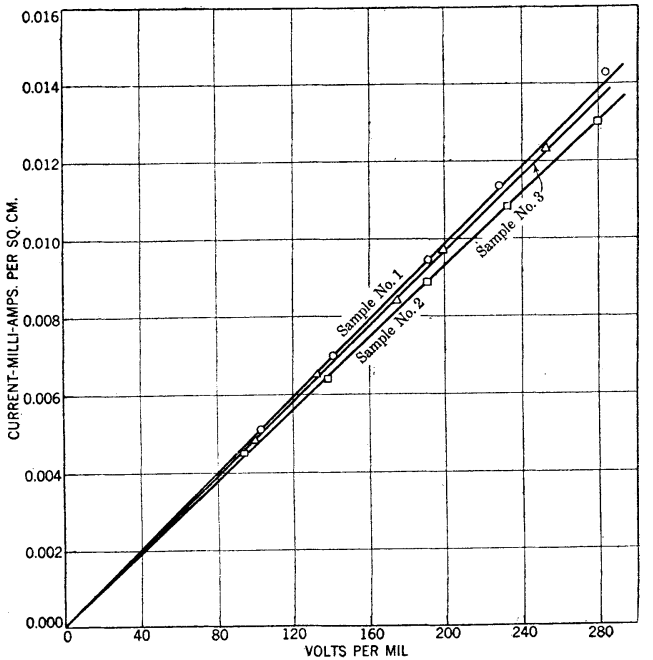

Fig. 9-Twelve-Mil Black Varnished Cloths

Comparative curves showing current vs. volts per mil-for three different kinds at 100 deg. cent. -60 cycles - sine wave-total thickness: $1-0.1214$ in.; $2-0.1245$ in.; $3-0.1093$ in.

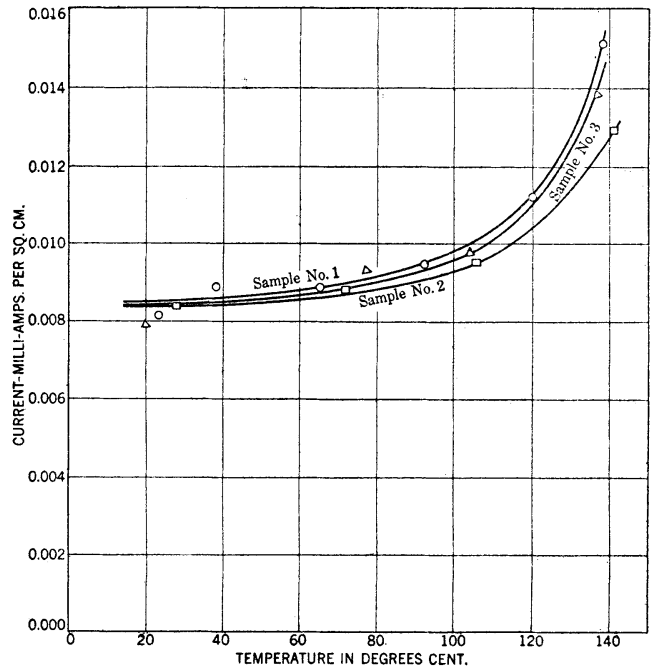

Fig. 10-Twelve-Mil Black Varnished Cloths

Comparative curves showing current vs. temperature for three different kinds at 200 volts per mil-60 cycles-sine wave-total thickness: $1-0.1214$ in.; $2-0.1245$ in.; $3-0.1093$ in. 
about four and a half times as great for the former cloth as for the latter. On the other hand, another sample of varnished cloth has yielded a power factor at $100 \mathrm{deg}$. cent. of about 13.5 per cent compared with about 20 per cent as shown in Fig. 11. These numbers show in a striking manner the difference likely to be

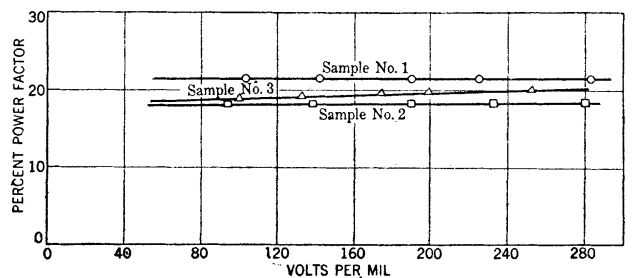

Fig. 11-Twelve-Mil Black Varnished Cloths

Comparative curves showing per cent power factor vs. volts per mil for three different kinds at 100 deg. cent. -60 cycles-sine wave-total thickness; $1-0.1214$ in.;2-0.1245 in.; $3 \rightarrow 0.1093$ in.

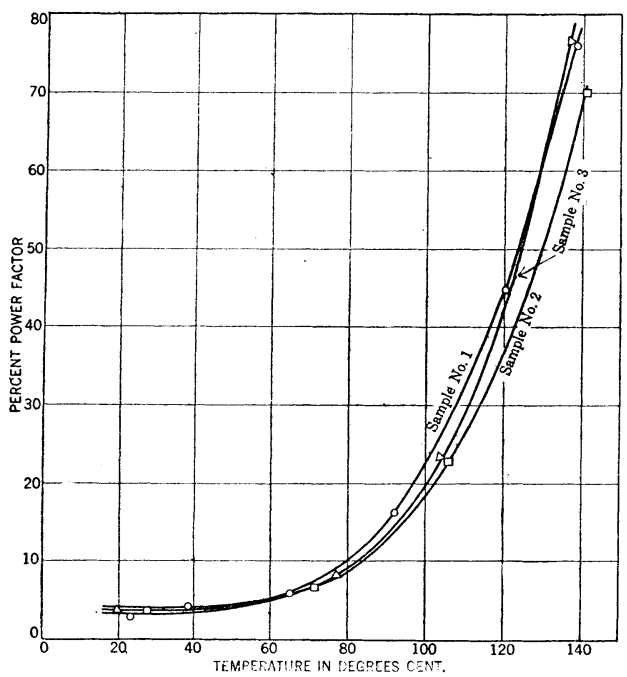

Fig. 12-Twelve-Mil Black Varnished Cloths

Comparative curves showing per cent power factor vs. temperature for three different kinds at 200 volts per mil-60 cycles- sine wave-total thickness: $1-0.1214$ in.; $2-$ 0.1245 in.; $3-0.1093$ in.

found in various kinds of varnished cloths, and they also show that tests of dielectric losses yield most valuable results. When a loss of 4.0 watts per cu. cm. is observed in a piece of insulation whose volume is about $250 \mathrm{cu}$. cm., it means that about a kilowatt is producing heat in it. Under such severe conditions a piece of insulation will always be punctured within a few minutes. 
B. Oil-Treated Pressboard. The samples of pressboard used were about $30 \mathrm{~cm}$. square and were cut from regular $3 / 32$-in. stock. After receiving a certain amount of drying, the samples were impregnated with good transformer oil for several hours. The results on the samples of pressboard, selected for this paper, were chosen so as to be able to show the characteristic curves and to compare the results for similar insulations under different conditions. Each of the test pieces, $A$ and $B$, (see Fig. 1)

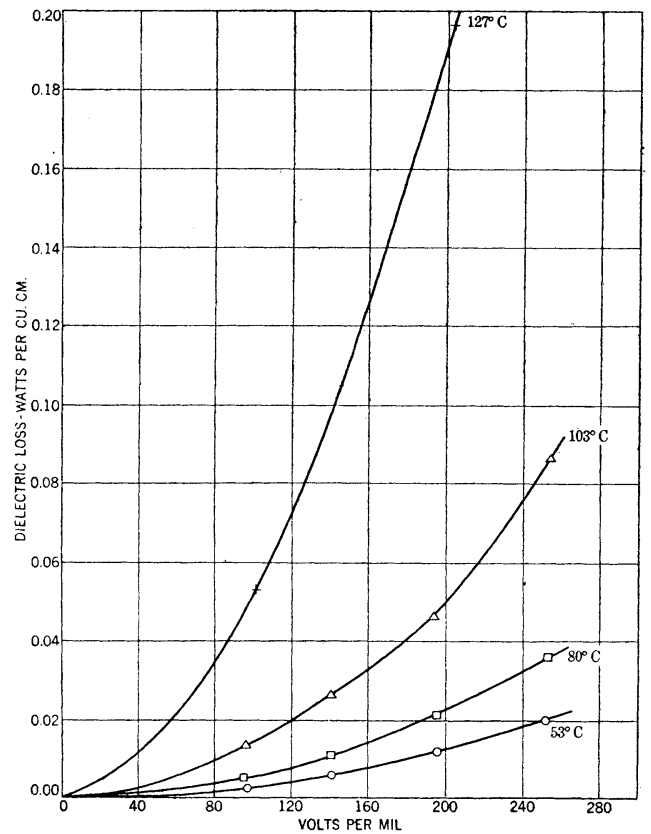

Fig. 13-Sample No. $1-3 / 32$-in. Oil-Treated Pressboard

Comparative curves showing dielectric loss vs. volts per mil at four different temperatures 60 cycles-sine wave- total thickness 0.193 in.

consisted of one sheet of oil-treated pressboard of the dimensions given above.

Figs. 13 to 18 , inclusive, show a set of curves taken on pressboard sample No. 1. The figures which have temperature as the abscissas were obtained from those having volts per mil as their abscissas. Attention should be called to the fact that the power factor was observed not to change with voltage for this sample at $53 \mathrm{deg}$. cent. and $80 \mathrm{deg}$. cent. For this reason one photograph only was taken at each of these two temperatures. These two power factors were used in making calcula- 


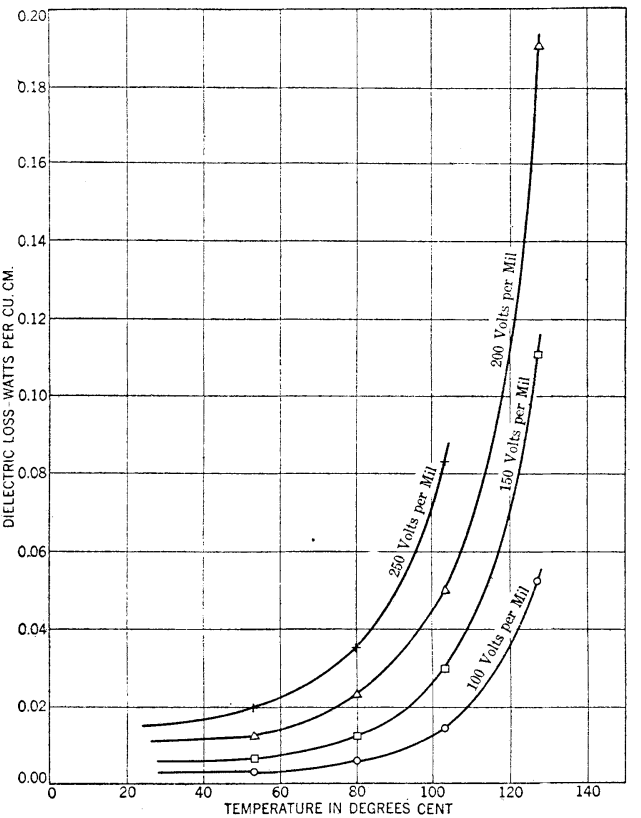

Fig. 14-Sample No. 1-3/32-In. Oil-Treated Pressboard

Comparative curves showing dielectric loss vs. temperature at four different voltages60 cycles - sine wave-total thickness 0.193 in.

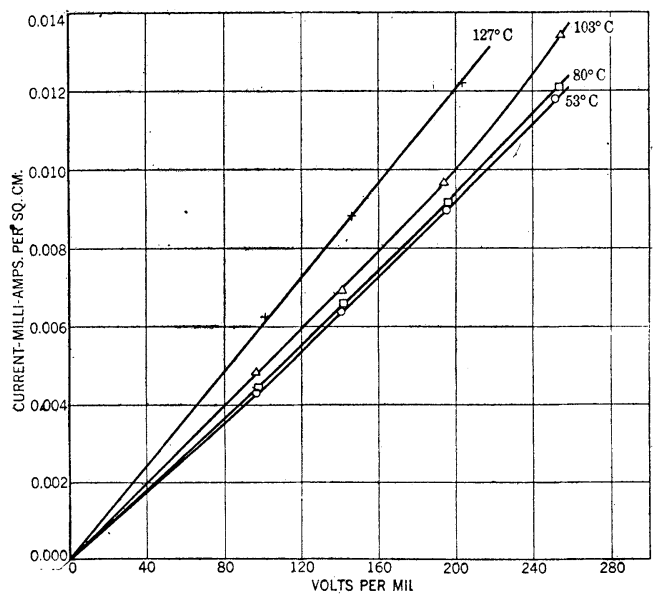

Fig. 15-Sample No. 1-3/32-in. Oil-Treated Pressboard

Comparative curves showing current vs. volts per mil at four different temperatures60 cycles-sine wave-total thickness 0.193 in. 
tion of watts at the different voltages for these two temperatures. Such a procedure as this would not be justified if the power factor changed with the applied voltage.

All the current curves shown in Fig. 15, with the exception

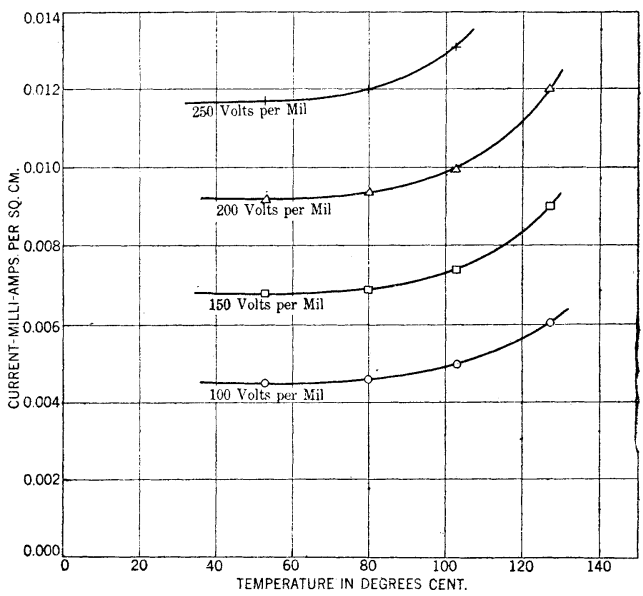

Fig. 16-Sample No. $1-3 / 32$-in. Oil-Treated Pressboard

Comparative curves showing current vs. temperature at four different voltages-60 cycles-sine wave- total thickness 0.193 in.

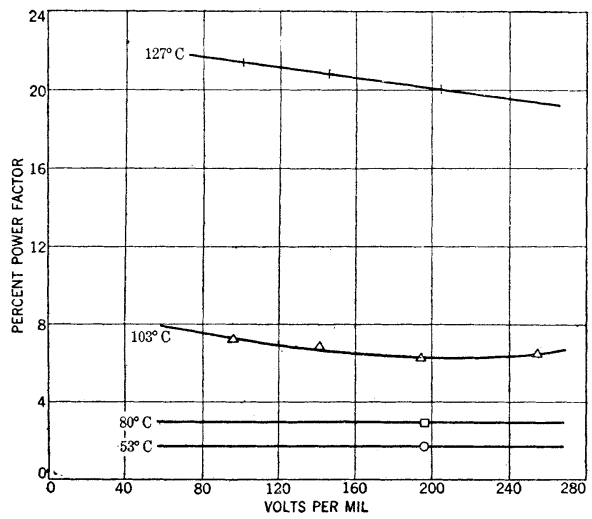

Fig. 17-Sample No. 1 -3/32-in. Oil-Treated Pressboard

Comparative curves showing per cent power factor vs. volts per mil at four different temperatures-60 cycles-sine wave-total thickness 0.193 in.

of the one at 127 deg. cent., curve upward near the upper ends, thus showing that the insulation was weakening. After taking the reading at 204 volts per mil and 127 deg. cent., the voltage was increased to secure a reading at 250 volts per mil, but before it could be taken the pressboard broke down. 
Results on two other samples (No. 2 and No. 3) of oil-treated pressboard, of the same kind as sample No. 1, are shown in Figs. 19 to 24 inclusive. These are for comparison with sample No. 1. Curves are not given for samples No. 2 and No. 3 showing dielectric loss, current, and power factor plotted against temperature. These three quantities, however, are plotted against voltage at $28 \mathrm{deg}$. cent., $60 \mathrm{deg}$. cent. and $85 \mathrm{deg}$. cent. The effect of temperature, therefore, up to $85 \mathrm{deg}$. cent. can be noticed and a comparison made with sample No. 1 .

It is worth while to compare the losses of samples No. 2 and No. 3 here. Considering the curves in Figs. 19 and 22, it it seen that at $27 \mathrm{deg}$. cent. and $28 \mathrm{deg}$. cent. the losses for sample No. 2 are about half of those for sample No. 3 at the higher

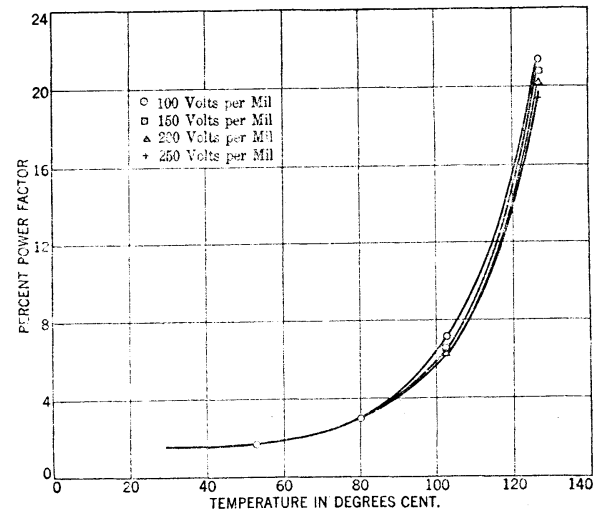

Fig. 18-Sample No. 1-3/32-in. Oil-Treated Pressboard

Comparative curves showing per cent power factor vs. temperature at four different voltages-60 cycles-sine wave-total thickness 0.193 in.

voltages, while at the lower voltages the reverse is true. At $60 \mathrm{deg}$. cent. the losses in the former sample are about onetenth of those for the latter sample at the higher voltages, but at the lower voltages they are about one-third as large. For the higher voltages the losses in sample No. 2 at 85 deg. cent. are about one-thirtieth of those in sample No. 3 at the same temperature, but they are about one-eighth as much at the lower voltages for the same temperature. These numbers show that temperature has an enormous effect on sample No. 3 compared with sample No. 2. They also show that a peculiar phenomenon of some nature occurs as the applied voltage is increased, otherwise the above peculiarities would not occur. This same effect is present at the higher temperatures because 


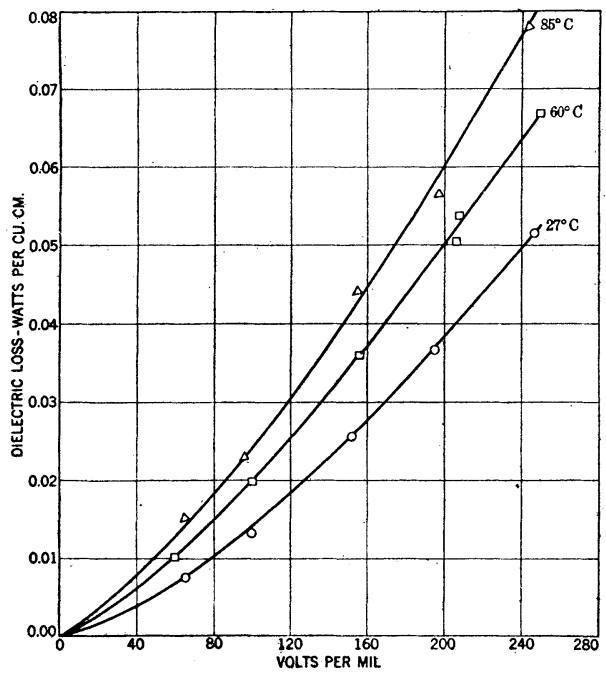

Fig. 19-Sample No. 2-3/32-In. Oil-Treated Pressboard

Comparative curves showing dielectric loss vs. volts per mil at three different temperatures; 60 cycles-sine wave-total thickness 0.1855 in.

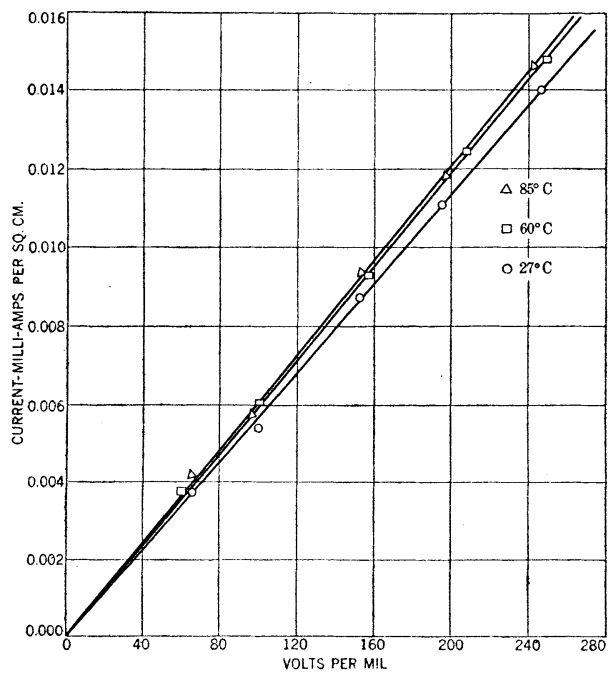

Fig. 20-Sample No. $2-3 / 32$-in. Oil-Treated Pressboard

Comparative curves showing current vs. volts per mil at three different temperatures60 cycles-sine wave-total thickness 0.1888 in. 


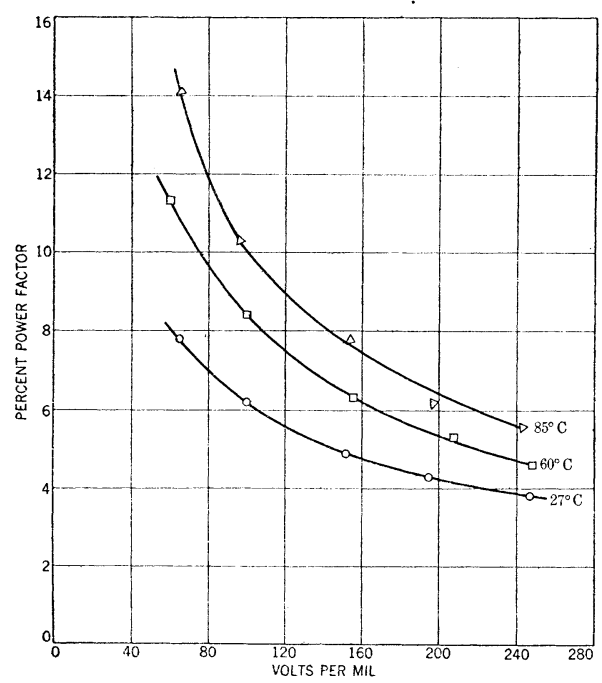

Fig. 21-Sampie No. 2-3/32-in. Oil-Treated Pressboard

Comparative curves showing per cent power factor vs. volts per mil at three different temperatures-60 cycles-sine wave-total thickness $0.1855 \mathrm{in}$.

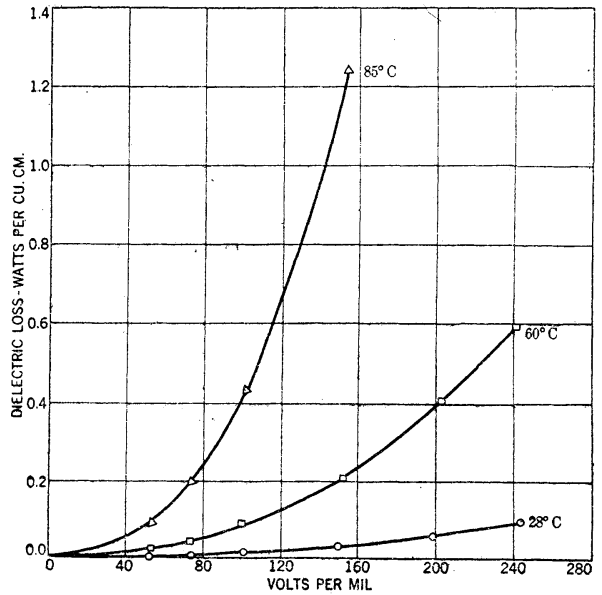

Fig. 22-Sample No. 3-3/32-in. Oil-Treated Pressboard

Comparative curves showing dielectric loss vs. volts per mil at three different tempera. tures-60 cycles-sine wave-total thickness 0.199 in. 
the ratio of the losses in the two samples is much less at the lower voltages than at the higher ones. These peculiarities observed for the losses are due to the decrease in power factor with increasing voltage for sample No. 2, as shown in Fig. 21. The set of curves for sample No. 2 shows that the pressboard was not weakening rapidly as the temperature was increased, but those for sample No. 2 show very large weakening effects due to increase of temperature.

One is surprised to observe such large variations in the losses, power factors, and current values for the same insulations

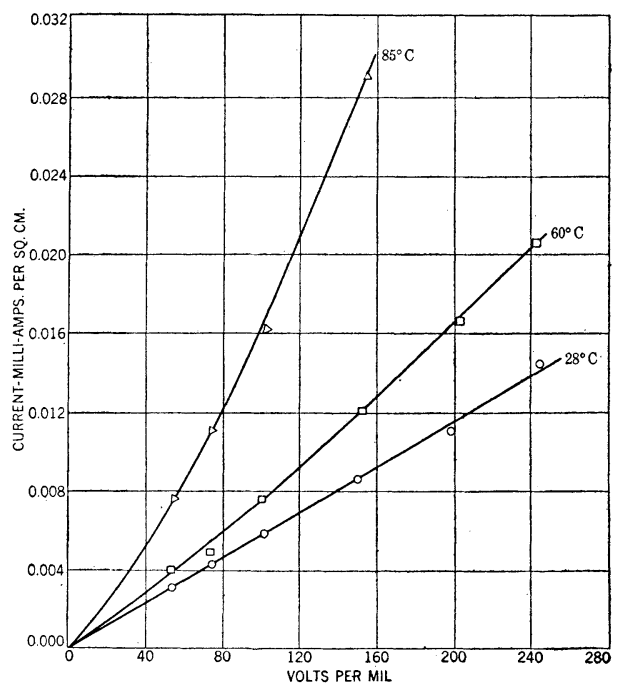

Fig. 23-Sample No. 3-3/32-in. Oil-Treated Pressboard

Comparative curves showing current vs. volts per mil at three different temperatures60 cycles-sine wave-total thickness 0.199 in.

under the same voltage and temperature conditions. The explanation of these variations is found in the quantity of absorbed moisture the samples contained. These three samples of oiltreated pressboard contained different amounts of absorbed moisture and for this reason their electrical properties were quite different. Samples No. 1, No. 2 and No. 3 contained 1.0 to 1.5 , about 0.5 and about 5.4 per cent free moisture, respectively. Since sample No. 2 had considerable drying it may be that certain effects were produced, due to this, that caused the power factors to behave as shown in Fig. 21. This will be referred to in the next section, dealing with a study of the 
experimental results. It may be asked, then, how much of the losses, power factors, and current, is due to moisture and how much is due to the material itself. The answer to this question has been determined as shown in the next section.

C. Effect of Moisture in Oil-Treated Pressboard. In order to determine how the losses, power factors, and current for oiltreated pressboard are affected by the quantity of absorbed moisture, a number of samples of the same kind of pressboard as tested above was taken. These samples were about $30 \mathrm{~cm}$. by $35 \mathrm{~cm}$. cut from the regular $3 / 32$-in. stock. They were placed in a closed can for about two weeks just prior to begin-

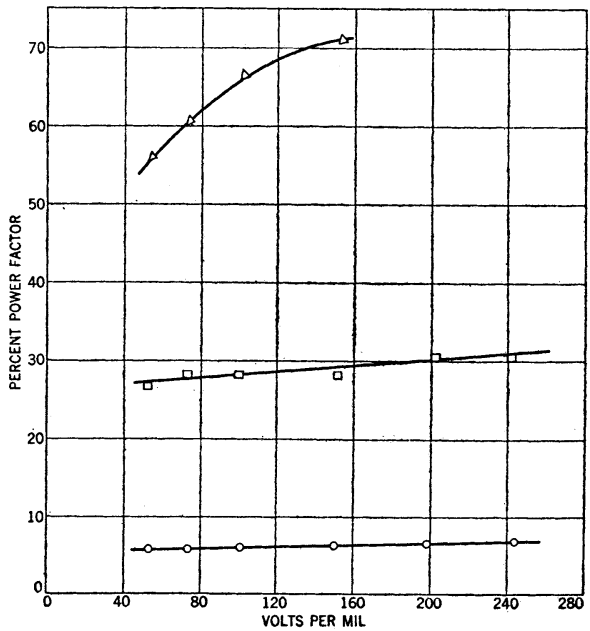

Fig. 24-Sample No. 3-3/32-in. Oil-Treated Pressboard

Comparative curves showing per cent power factor vs. volts per mil at three different temperatures-60 cycles-sine wave-total thickness 0.199 in. Upper curve, 85 deg. cent.; middle curve, 60 deg. cent.; lower curve, 28 deg. cent.

ning the tests. During this period the samples had sufficient time to liberate or absorb moisture until all of them contained equal percentages.

When a test was ready to be made, two sheets were taken out of the can. Two strips about $2.5 \mathrm{~cm}$. by $30 \mathrm{~cm}$. were cut from each sheet, and from the four strips thus obtained, eight samples, $2 \mathrm{~cm}$. by $5 \mathrm{~cm}$., were cut from various places. These small samples were placed, at once, in an air-tight weighing bottle. The test samples, $30 \mathrm{~cm}$. square, were weighed at the same time the moisture samples were put in the air-tight weighing bottle. The square samples were then dried in air at 100 deg. cent. until they had lost the desired amount of mois- 
ture. They were then weighed in an air-tight receptacle, and their weight determined before any moisture could be absorbed. After weighing, the samples were placed at once in good transformer oil at about $65 \mathrm{deg}$. cent. in order to be sure that no moisture was absorbed by exposure to the air and to avoid the possibility of liberating appreciable quantities of water during impregnation at $65 \mathrm{deg}$. cent. From these data, the percentage loss of weight due to vaporizing moisture was determined. By securing the weights of these small moisture samples before and after drying them at about $90 \mathrm{deg}$. cent. in vacuo, it was possible to calculate the total free moisture they contained. Phosphorus pentoxide tubes were used to absorb the water liberated during the drying. This percentage of free moisture in the small samples was taken to represent the percentage cf absorbed moisture in the test pieces. Subtracting from this value the value obtained above for the loss of weight due to drying in air at $100 \mathrm{deg}$. cent., one obtained the percentage absorbed moisture still remaining in the test pieces during the tests. Absolutely correct results cannot be obtained by this method, but approximately correct percentages can be secured.

In Figs. 25, 26 and 27 will be found results taken at 200 volts per mil and at three different temperatures on several sheets of pressboard containing different percentages of moisture. It is to be regretted that more points are not available through which the curves may be drawn. Sufficient points, however, were taken to give the general shape of the curves and to show the enormous influence absorbed moisture has on the losses, power factors, and current values for porous insulation capable of absorbing moisture. The value 0.5 per cent moisture was estimated from previous experience. Attention should be called to the point at 99 per cent power factor given in Fig. 27. At 150 volts per mil the recorded power factor was 99 per cent, but while attempting to take the reading at 200 volts per mil the test pieces broke down. From previous experience, therefore, it was known that the power factor at 200 volts per mil and 85 deg. cent. could not have been less than 99 per cent. For this reason this point was used to give the direction of the curve near 100 per cent power factor.

At lower voltages (50 to 100 volts per mil) there is a decided "dip" in the curves similar to those shown in Fig. 27 at about 2.0 per cent moisture. At the higher voltages $(250$ volts per 
mil) and temperatures this "dip" is not present. Too much space would be required to show all of these effects by means of curves, and for this reason they are omitted. It is questionable, therefore, whether all the moisture should be removed or not. Other interesting points will be brought out in the study of the experimental results given next.

\section{Study of Experimental Results}

Empirical Equations. In order to study the subject more carefully, it will be advantageous to express the results in the

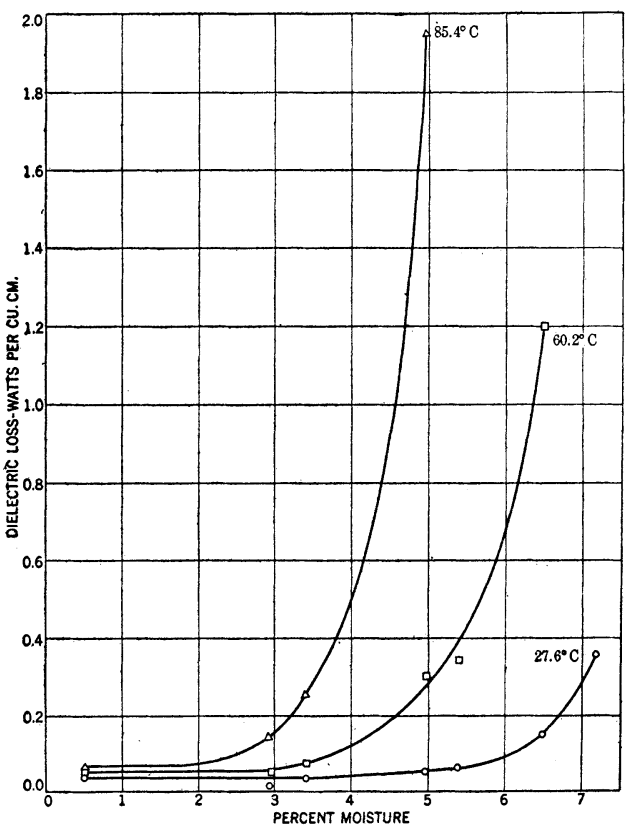

Fig. 25-Oil-Treated 3/32-in. Pressboard

Comparative curves showing dielectric loss vs. per cent moisture at three different temperatures and at 200 volts per mil-60 cycles-sine wave-average thickness of the seven samples used was 0.196 in.

form of empirical equations. By this means, a comparison of the results leads to a better understanding of them and will show clearly the fundamental nature of all of the results given in this paper. In experimental results, the order in which the figures were given was dielectric loss, current, and power factor. This order will now be reversed, and equations for current and power factors followed by those for dielectric losses will be given as a function of the voltage, temperature, and per cent moisture. 


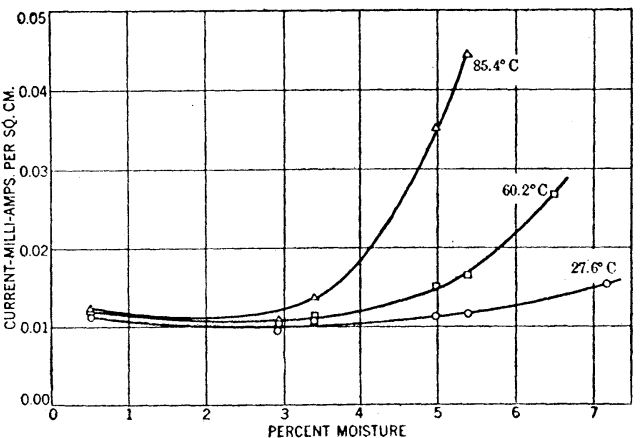

Fig. 26-Oil-Treated 3/32-in. Pressboard

Comparative curves showing current vs. per cent moisture at three different temperatures and at 200 volts per mil-60 cycles-sine wave-average thickness of the seven samples was 0.196 in.

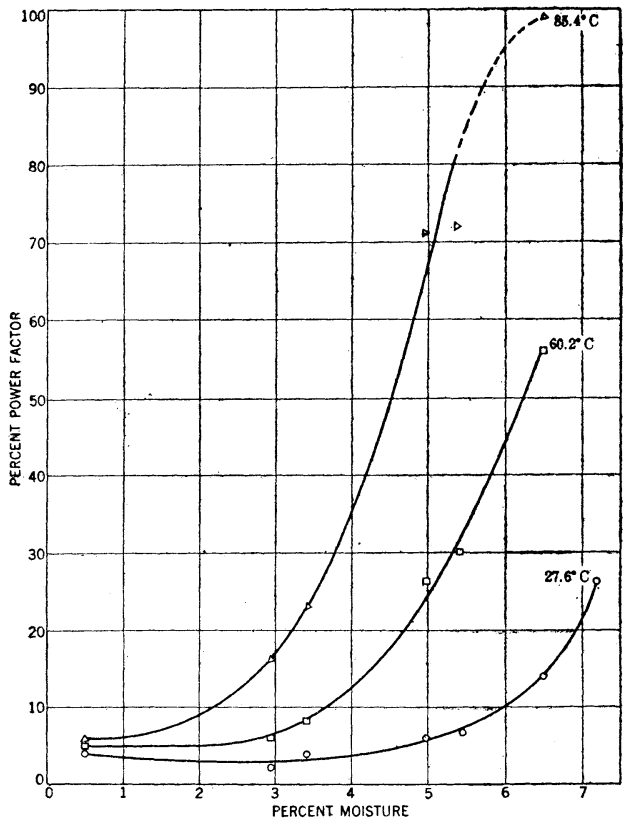

Fig. 27 -Oll-Treated 3/32-in. Pressboard

Comparative curves showing percent power factor vs. per cent moisture at three different temperatures and at 200 volts per mil-60 cycles-sine wave-average thickness of the seven samples was 0.196 in. 


\section{(a) Voltage Equations.}

1. Current vs, volts per mil. It has been found that the current values, $I$, as given by Figs. 9, 15, 20, and 23, can be expressed as a function of the voltage, $V$, by the general equation

$$
I=K_{1} V+K_{2} V^{n}
$$

Ordinarily, at about room temperature and for fairly good insulation, the results can be expressed by the first term of equation (20), so that the second term becomes zero. For these cases

$$
I=K_{1} V
$$

The second term of equation (20) represents the deviation from a straight line which is tangent to the curve at the origin. If $I$ is expressed in milliamperes per sq. $\mathrm{cm}$. and $V$ in volts per mil, the following equations express the results nicely:

Fig. 9 Varnished cloth-Sample No. $1-I=0.0000497 \mathrm{~V}$

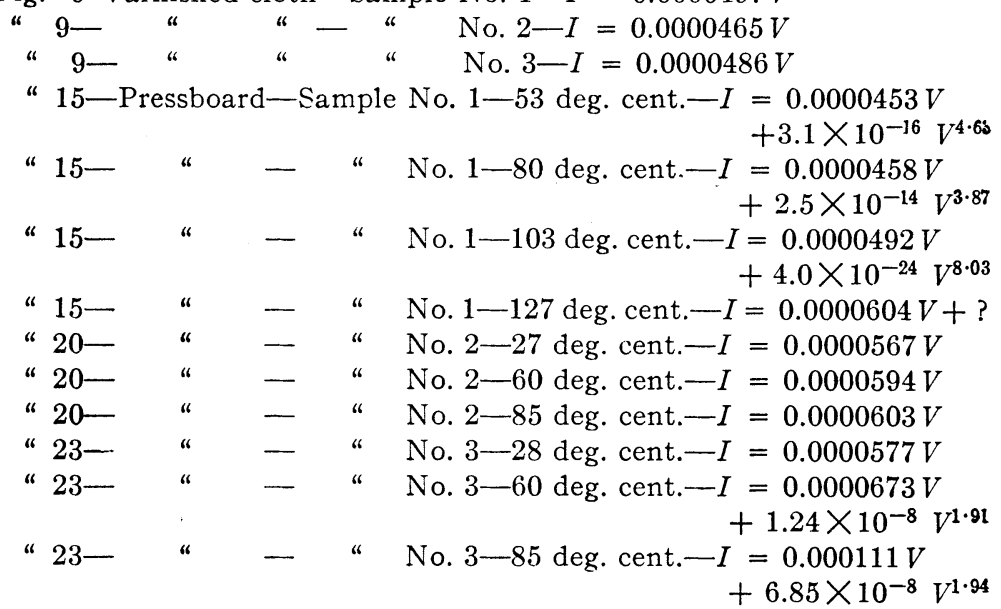

Equation (21) shows that the current varies directly as the voltage. From the above equations, this is seen to be true with all samples tested at room temperature, and also true for some samples tested at higher temperatures. This means that the admittances of the test samples were constant when this equation was satisfied. In order for the admittance of a piece of insulation to remain constant the capacity and resistance must not change or they must change in such a way as to leave the admittance constant. It is more reasonable to believe that the first condition would be fulfilled rather than the second. 
When equation (21) fails to represent the current passing through the insulation, then equation (20) will do it. When the current is rising faster than the voltage, as indicated by equation (20), it means that the insulation is weakening, and implies less satisfactory material than if the weakening effect were not present. It is doubtful if any insulation will prove satisfactory that needs equation (20) to represent the current passing through it. The equations tabulated above show that some of them are of the form (20) and, in these cases, the material broke down under test, while the others did not puncture. This suggests, therefore, that it is not at all unreasonable to judge the electrical value of an insulation merely by making observations of the current alone. The second term of equation (20) represents almost wholly, if not entirely, energy current. Part of the constant term also represents energy current. Pressboard sample No. 3 contained 5.38 per cent moisture, while sample No. 2 contained about 0.5 per cent, and one will notice from the above equations that this extra amount of moisture is responsible for large energy currents because the dielectric losses, as previously pointed out, were much larger for the former sample.

2. Power factor vs. volts per mil. The power factors, as given by Figs. 11, 17, 21, and 24, can be expressed as a function of the voltage, $V$, by one of the following forms of equations:

$$
\begin{aligned}
& P=K \\
& P=K_{1}+K_{2} V \\
& P=K_{1}-K_{2} V \\
& P=K_{1}-K_{2} V^{-n} \\
& P=K_{1}+K_{2} \epsilon^{-a v}
\end{aligned}
$$

$\epsilon$ is the base of the Napierian logarithms.

If $P$ is the per cent power factor, and $V$ the volts per mil, then the following equations represent the various curves given in the figures referred to above:

Fig. 11-Varnished cloth-Sample No. $1-P=21.5$
" 11
" - "
No. $2-P=18.2$
"11- " "
" - "
No. $3-P=18.2+0.0068 \mathrm{~V}$
“ 17-Pressboard-Sample No. $1-53$ deg. cent. $-P=1.7$
“ $17-$
No. $1-80$ deg. cent. $-P=3.0$
“ 17
-
No. $1-103$ deg. cent. $-P=$ ?
"17-
No. $1-127$ deg. cent. $-P=22 \cdot 8-0.0136 \mathrm{~V}$ 


\begin{tabular}{|c|c|c|c|c|c|}
\hline Fig. $21-$ & “ & - & “ & No. $2-27$ deg. cent. $-P$ & $\begin{array}{l}=3.0 \\
+8.2 \epsilon^{-0.00405 v}\end{array}$ \\
\hline “ $21-$ & “ & - & “ & No. $2-60$ deg. cent. $-P$ & $\begin{array}{l}=3.5 \\
+10.3 \epsilon^{-0.00372 v}\end{array}$ \\
\hline " $21-$ & “ & - & “ & No. $2-85$ deg. cent. $-P$ & $\begin{array}{l}=4.0 \\
+16.5 \epsilon^{-0.00462 v}\end{array}$ \\
\hline " $24-$ & “ & - & $"$ & No. $3-28$ deg. cent. $-P$ & $=5.4+00585 \mathrm{~V}$ \\
\hline " $24-$ & “ & - & “ & No. $3-60$ deg. cent. $-P$ & $=26.3+0.0196 \mathrm{~V}$ \\
\hline " $24-$ & “ & - & “ & No. $3-85$ deg. cent. $-P$ & $=100$ \\
\hline
\end{tabular}

Referring to Fig. 17, it will be seen that no equation is given for the curve at $103 \mathrm{deg}$. cent. This curve first has an apparent decrease and then an increase of power factor. Curves of this type require a combination of two equations to express them.

The equations which represent the power factor as a function of the voltage are quite varied over the range of conditions met with in the tests reported in this paper. The equations hold closely over the range of the tests; some of them cannot hold for low voltages, while others cannot apply for high voltages. They are valuable in so far as they give one an idea of the forms of the equations when the power factors are measured over such wide conditions as were met in these tests. When equation (22) holds, the power factor does not change with voltage. From the numerical equations above, it is seen that this equation applied in several cases. Insulation which behaves in this way will prove satisfactory as far as dielectric losses are concerned. Equations (23) and (25) are for power factors which increase with voltage, and (24) and (26) are for those which decrease with voltage. The numerical equations given shown that all four of the forms are required to express the results. The particular form of equation which will hold depends on the conditions of the test and on the nature of the insulation. It depends on these two things, because the power factor varies from zero to 100 per cent. In order for an equation to represent the power factor completely, it must be one which has these two limits as its asymptotes. The particular form of equation, then, will be influenced by the position of the power factor with respect to these two limits. Both the conditions of the test and the nature of the insulation determine the value of the power factor, as has already been pointed out.

The power factor changes because the capacity and resistance vary. The results show, therefore, that in some cases these do not change, while in other cases, large variations are observed with voltage. One would think the increase in power 
factors is due to heating effects. But the losses always produce heating effects, which are small in many cases, and hence, the power factor should always increase, if it changes at all with voltage. It was pointed out, however, that a surprisingly large decrease in power factor with increasing voltage was observed in the case of well-dried oil-treated pressboard. In this case the application of high-voltage stresses produces effects, the nature of which is not fully known. Just as mica filings are lined up under the influence of an electric field, so are the water and other movable materials in an insulation influenced. It may be that herein lies the explanation of certain electrical phenomena observed in connection with insulation.

3. Watts vs. volts per mil. It is found that in almost all cases the watts $(W)$ can be expressed as a function of the voltage $(V)$. fairly well by the equation

$$
W=K V^{n}
$$

Referring to equation (19), if the power factor is independent of the voltage and the current directly proportional to it, then $W$ should vary directly as the square of the voltage. This law is frequently assumed to be true and many calculations are made depending on this assumption. The table of equations given below will show that this square law does not hold in many cases. If the power factor increases with increasing voltage and the current varies directly as the voltage or faster than it, then the exponent $n$ in equation (27) must be greater than two. The current has not been observed to vary less than the first power of the voltage, but the power factor frequently decreases with increasing voltage. In these cases, the exponent $n$ must be less than two. The following table will show all three of these instances. $W$ is expressed in watts per cu. $\mathrm{cm}$. and $V$ in volts per mil.

Fig. 7 -Varnished cloth-Sample No. $1-W=4.90 \times 10^{-6} V^{1.98}$

\begin{tabular}{|c|c|c|c|c|}
\hline $7-$ & “ & & & No. $2-W=4.40 \times 10^{-6} V^{1.95}$ \\
\hline $7-$ & “ & & & No. $3-W=1.87 \times 10^{-6} V^{2 \cdot 1 \hat{s}}$ \\
\hline \multicolumn{5}{|c|}{$13-$ Pressboard- Sample No.1-53 deg. cent. $-W=0.235 \times 10^{-6} V^{2.05}$} \\
\hline $13-$ & \& & - & " & No. $1-80 \mathrm{deg}$. cent. $--W=0.665 \times 10^{-6} V^{1 \cdot 97}$ \\
\hline $13-$ & " & - & “ & No. $1-103$ deg.cent. $-W=2.47 \times 1$ \\
\hline $13-$ & “ & - & “ & No. $1-127$ deg.cent. $-W=9.45 \times 10^{-6} V^{1 \cdot 87}$ \\
\hline 19 - & " & - & " & No. $2-27$ deg. cent. $-W=15.6 \times 10^{-6} V^{1 \cdot 47}$ \\
\hline $19-$ & “ & - & “ & No. $2-60$ deg. cent: $-W=45.5 \times 10^{-6} V^{1 \cdot 32}$ \\
\hline $19-$ & " & - & " & No. $2-85$ deg. cent. $-W=52.5 \times 10^{-6} V^{1 \cdot 33}$ \\
\hline $22-$ & " & - & “ & No. $3-28$ deg. cent. $-W=0.210 \times 10^{-6} V^{2 \cdot 37}$ \\
\hline $22-$ & “ & - & “ & No. $3-60$ deg. cent. $-W=2.75 \times 10^{-6} V^{2 \cdot 14}$ \\
\hline $22-$ & " & - & " & No. $3-85$ deg. cent. $-W=3.85 \times 10^{-6} V^{2.52}$ \\
\hline
\end{tabular}


This table shows that the losses vary at least from the 1.32 to the 2.52 power of the voltage, depending on the condition of the test and on the nature of the insulation. Comparing the current and power factor curves with the corresponding loss curves, it will be observed that the "square" law holds fairly well where it should hold theoretically. When the power factor decreases with increasing voltage and the current varies directly as the voltage it will be noted that the same equation holds but the exponent is considerably less than two. In other cases, on account of the manner in which the current and power factor vary with the voltage, the exponent $n$ is considerably greater than two. The samples of pressboard which contained the largest percentage of moisture gave the largest values for $n$, while the well-dried sample (No. 2) gave the smallest. As has been suggested already, pressboard sample No. 1 probably contained a little more moisture than sample No. 2 , and it is seen that the exponent has larger values for the former sample than it has for the latter. In addition to this effect of moisture on the exponent $n$, the temperature at which the tests are made also affects the values of the exponent. In the same way, the moisture and temperature influences the value to be assigned for the constant $K$.

(b) Temperature Equations.

1. Current vs. temperature. The curves in Fig. 10 showing the current vs. temperature for varnished cloth can be represented by the equation

$$
I=K_{1}+K_{2} \epsilon^{a v}
$$

while those for pressboard given in Fig. 16 can be represented by

$$
I=K_{1}+K_{2} T^{n}
$$

It has already been mentioned that the points for the curves given in Fig. 10 do not form smooth curves, and for this reason, it is doubtful if equation (28) would represent the curves if the points were more consistent. It may be said that out of a large number of cases tried, equation (29) has been found to hold. For this reason, the latter equation is to be considered as the more probable one, to express the results. The following numerical equations express the results given in Figs. 10 and 16. $T$ is expressed in degrees cent. and $I$ in milliamperes per sq. $\mathrm{cm}$. 
Fig. 7-Varnished cloth-Sample No. $1-I=0.0085+3.1 \times 10^{-5} \epsilon^{0 \cdot 165 \mathrm{~T}}$

"7- " " $"$ "No. $2-I=0.0084+2.2 \times 10^{-5} \epsilon^{0.164 \mathrm{~T}}$

"7- " $\quad$ - " No. $3-I=0.0084+2.7 \times 10^{-5} \boldsymbol{\epsilon}^{0.165 \mathrm{~T}}$

" 16-Pressboard-Sample No. 1-100 VPM-I $=0.0045+5.3$

$\times 10^{-17} \mathrm{~T}^{5.95}$

" $16-\quad$ - " No. $1-150 V P M-I=0.0068+1.55$

$\times 10^{-18} T^{6.75}$

" $16-\quad$ - "No. $1-200$ VPM-I $=0.0092$

" 16 - $\quad$ "No. $1-250 \mathrm{VPM}-I=0.0117$

$$
+1.36 \times 10^{-16} T^{5.95}
$$

The constant terms in these equations represent that part of the current which does not change with temperature. The second terms, however, are seen to increase rapidly with the temperature. These second terms represent weakening effects in the insulation, which is finally broken down due to them. These terms, then, probably represent almost entirely energy current, which is seen to increase about as the 6th power of the temperature. Consequently, for large values of $T$ the weakening effects increase very rapidly. At low temperatures, the weakening effects are not so of much importance as at the higher temperatures. These same effects are noted for power factors and losses.

2. Power factor vs. temperature. Since the current can be represented as some constant plus a term to represent weakening effects, due to increased temperature, it is natural to look for the same kind of a law to represent the power factor as a function of the temperature. Referring to Figs. 12 and 18, it is seen that the shape of the curves is similar to that of the current curves showing the temperature effect. As a matter of fact, if $P$ is the per cent power factor and $T$ the degrees cent., then

$$
P=K_{1}+K_{2} T^{n}
$$

for the curves given in Figs. 12 and 18. The numerical equations for the curves in Fig. 12 on varnished cloth are:

$$
\begin{gathered}
\text { Sample No. } 1-P=3.5+1.20 \times 10^{-9} T^{4 \cdot 60} \\
\text { " No. } 2-P=3.5+1.80 \times 10^{-9} T^{4 \cdot 45} \\
\text { “ No. } 3-P=3.5+0.29 \times 10^{-9} T^{4 \cdot 85}
\end{gathered}
$$

The curves shown in Fig. 18 are so nearly the same that the following equation represents an average curve through the points at the various temperatures:

$$
P=1.6+1.25 \times 10^{-12} T^{5 \cdot 75}
$$


These equations hold nicely over the range tested, but they could not represent a curve extending from 0 to 100 per cent power factor for reasons pointed out in the section dealing with the voltage equations. These equations show that the weakening effects, due to increase of temperature, are causing large increases in the power factors as well as in the magnitude of the currents.

3. Watts vs. temperature. It would seem reasonable to multiply the current and power factor equations together at any constant voltage in order to express the watts as a function of the temperature. This would yield the desired equation but since the current and power factor equations are alike for the curves given in this paper, it is to be expected that loss equations will be of the same general form. This expectation is fulfilled, for if $W$ is the watts per cu. $\mathrm{cm}$. and $T$ the degrees cent. as before, then

$$
W=K_{1}+K_{2} T^{n}
$$

The constant term represents the loss which does not change with temperature, while the second term is accounted for by the weakening effects due to the influence of temperature. The following equations show these effects to increase rapidly with temperature, and the curves in Figs. 8 and 14 represent the results graphically.

Fig. 8-Varnished cloth-Sample No. $1-W=0.020+6.8 \times 10^{-13} T^{5 \cdot 15}$

"8- " " " " No. $2-W=0.025+3.5 \times 10^{-13} T^{5.25}$

"8- " " - " No. $3-W=0.020+9.7 \times 10^{-13} T^{5 \cdot 10}$

" 14-Pressboard-Sample No. $1-100$ VP $M-W=0.0030+7.6$

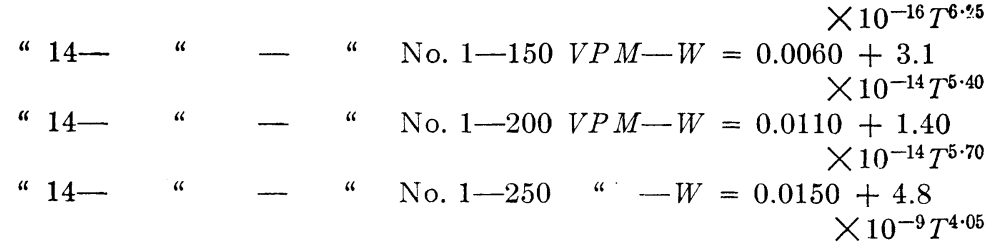

It should be stated that these equations do not fit the curves exactly, for at the higher temperatures, the equations give too low results. This tends to show that the temperature of the insulation was higher than that actually recorded, thus producing greater losses than indicated by the equations. The energy dissipated in the insulation was sufficient for high dielectric losses to produce considerable heating effects. Now, these high losses occur at high temperatures and the rise of tempera- 
ture of the insulation above that of the surrounding oil becomes appreciable only at the higher temperatures, say above $100 \mathrm{deg}$. cent. If this rise of temperature could have been taken into consideration, then it is probable that equation (31) would apply quite closely. Taking into account the deviations of the equations from the experimental curves, they seem to indicate that the rise of temperature of the test pieces above the surrounding oil was probably five or six degrees cent. This increase of temperature occurred during the time the potential was applied, which was not more than a few minutes in most cases.

It is to be noted that exponent $n$ for equation (31) is about equal to that for equations (29) and (30). The weakening effects, then, due to temperature, affect the current, power factor, and loss in the same way and they can be represented by the same general type of equation, thus showing the fundamental nature of the effects due to temperature.

(c) Moisture Equations.

1. Current vs. per cent moisture. The general shape of the moisture curves shown in Figs. 25, 26, and 27 leads one to suspect that they are of the same nature as the temperature curves and that the same general form of equation ought to apply to both sets. It has been pointed out that there appears to be a noticeable increase in the power factors and losses at the lower voltages ( 50 voits per mil) for well-dried samples of pressboard. At the higher voltages (200 to 250 volts per mil) this increase is not so noticeable as shown in the above figures. Consequently it is impossible for the general form of the temperature equations to apply exactly for moisture. Neglecting this peculiarity and considering the weakening effects due to the presence rather than the absence of moisture, the same general type of equation holds for both the temperature and moisture effects. So that, if $X$ is the per cent moisture absorbed in the pressboard and $I$ the current in milliamperes per sq. cm., then

$$
I=K_{1}+K_{2} X^{n}
$$

The numerical equations for the curves in Fig. 26 are

$$
\begin{aligned}
& \text { At } 27.6 \mathrm{deg} \text {. cent. }-I=0.0101+9.0 \times 10^{-8} X^{4 \cdot 40} \\
& \text { " } 60.2 \mathrm{deg} \text {. cent. }-I=0.0105+9.9 \times 10^{-8} X^{5 \cdot 20} \\
& \text { " } 85.4 \mathrm{deg} \text {. cent. }-I=0.0110+30.5 \times 10^{-8} X^{5 \cdot 60}
\end{aligned}
$$

It is to be observed that these equations also show that moisture causes weakening effects in insulation in much the same way 
that increase in temperature does. In both cases the values for the exponent $n$ are about the same, showing that weakening effects increase even as much as the 5 th or 6 th power of the absorbed moisture.

2. Power factor vs. per cent moisture. The general form of the equation representing power factor vs. per cent moisture is

$$
P=K_{1}+K_{2} X^{n}
$$

It is seen to be of the form (32). It holds only over a limited range, perhaps up to 85 per cent power factor. This shows that the power factor is changing in much the same way the current does. The following equations apply to the curves shown in Fig. 27 :

$$
\text { At } \begin{aligned}
27.6 \text { deg. cent. }-P & =3.0+1.65 \times 10^{-5} X^{6 \cdot 00} \\
\text { " } 60.2 \text { deg. cent. }-P & =4.7+3.50 \times 10^{-3} X^{3 \cdot 90} \\
\text { " } 85.4 \text { deg. cent. }-P & =6.0+3.05 \times 10^{-2} X^{3 \cdot 30}
\end{aligned}
$$

These equations show that the effect of moisture on the power factor is the same as the effect on the current.

3. Watts vs. per cent moisture. The same form of equation also applies to the curves showing the dielectric loss vs. per cent moisture. That is,

$$
W=K_{1}+K_{2} X^{n}
$$

The same limitations are to be placed upon this equation as were put on equation (32). The following equations apply to those curves given in Fig. 25:

$$
\begin{aligned}
& \text { At } 27.6 \text { deg. cent. }-W=0.035+1.45 \times 10^{-9} X^{8 \cdot 55} \\
& \text { " } 60.2 \text { deg. cent }-W=0.050+2.65 \times 10^{-6} X^{5 \cdot 65} \\
& \text { " } 85.4 \text { deg. cent. }-W=0.061+1.25 \times 10^{-5} X^{6 \cdot 00}
\end{aligned}
$$

These equations show that the losses increase rapidly as the quantity of absorbed moisture increases. All of the moisture equations show clearly the harmful effects produced by it, and it is essential to look closely into this matter in studying insulation which absorbs moisture.

It may be said of the equations as a whole that the exponent $n$, and the constants, $K_{1}$ and $K_{2}$, are greatly affected by the voltage, temperature and moisture conditions. There does not appear, however, to be any definite relation between these quantities and the three variables dealt with in this paper. The equations reveal the fact that the nature of the increased conductivity is the same for both temperature and moisture. This lends strength to the belief that moisture may be responsible 
for a large part of the phenomena observed. This is also further strengthened by the fact that the currents, power factors, and losses, increase many fold in the neighborhood of $100 \mathrm{deg}$. cent. and especially above this temperature. This temperature is a critical point for water at atmospheric pressure, but it would require over $100 \mathrm{deg}$. cent. to boil water in extremely small capillary tubes such as exist in porous insulation. If the moisture is entrapped in an insulation that is only slightly porous, then it could not be eliminated by evaporation so easily. Consequently, when the temperature of the insulation is, say 125 deg. cent., the moisture may show decided increases in conductivity that do not show up below $100 \mathrm{deg}$. cent. Since most of the losses are due to the absorbed moisture it is reasonable to believe that they are to a great extent in the moisture itself rather than in the insulation. This means that the temperaturerise occurs in the former before it does in the latter. Not more than $12 \mathrm{cu} . \mathrm{cm}$. of moisture existed in any of the test samples considered in this paper and for this reason the losses could apparently produce marked changes in the insulation. As a matter of fact, probably little change took place in the material itself and almost the whole change probably was due to the increased conductivity of the moisture on account of the heating effects within it. It is advisable, therefore, to look carefully into the nature of the foreign material an insulation contains, whether this material be moisture or other harmful substances. The equations show that the weakening effects increase as the 5th or 6th power of the temperature and moisture. So that, if the moisture is present to only a few per cent, these effects become excessive and the increase of temperature magnifies them still more. With such an unstable condition of the insulation as here indicated, it is to be expected that the effective temperature of the insulation, for high losses, will be higher than recorded by a thermometer placed under the oil against the test terminal. For this reason the equations may not hold exactly over the whole range for the various curves. Considering everything, the equations represent the results as well as one can desire. As a whole, the results point to a conductivity of an electrolytic nature.

There are many other things to which attention might be given, but this will not be done in the present paper. It is to be hoped that in a future paper further results of the work on dielectric losses, especially regarding the effect of frequency on them, may be given. 
Accuracy of Results. It will be well to devote a short space to the consideration of the accuracy of the results given in this paper. Both the current and voltage can be measured to within one or two per cent, but the largest error is introduced by the measurement of the minor axes, $b^{\prime}$, of the ellipses on the photographic plates. Referring to the illustrations in Plate CXI, it will be seen that no great difficulty would be encountered in measuring $b^{\prime}$ for illustrations $3,4,5$ and 6 . The measurement of $b^{\prime}$ for photographs 1 and 2 might be in error as much as five per cent. If one desires to check the measurements given in the paper for these illustrations, he may do so in order to see how accurate the measurements can be made. Experience in making these measurements will be found valuable. It should be said that the measurements can be made on the originals with a greater precision than on these reproductions. For low power factors, as shown in the first two illustrations, each point for dielectric loss may be in error by $\sqrt{1^{2} \times 2^{2}+5^{2}}=5.5$ per cent. One, two, and five per cent are used, respectively, for the errors due to voltage, current, and power factor measurements. When points for a curve are taken it is probably true that a point taken off an average curve will not be in error by more than about 2.5 per cent. Certainly, with the larger power factors this precision can be obtained with the cyclograph. An accuracy of the cyclograph equivalent to this is quite satisfactory for the kind of work to which this apparatus is adapted.

\section{Conclusions}

The following conclusions are arrived at as a result of this investigation on dielectric losses:

1. The successful application of the cyclograph in determining dielectric losses in insulations is amply demonstrated by the results given in this paper.

2. For good insulation the current should vary directly as the applied voltage. If the current increases more rapidly than this, it will show weakening properties.

3. The dielectric losses vary over wide limits, depending on the conditions of the tests and the nature of the insulations. The losses show clearly the electrical value of an insulation.

4. The results given in the paper show that the power factor of insulation may vary from about 2 to 99 per.cent. The nature of the insulation and the conditions of the tests determine its value. 
5. It is shown that the watts do not vary as the square of the voltage, but may vary from the 1.32 to the 2.52 power of the voltage.

6. The weakening effects in insulation, as shown by the dielectric losses, power factors, and currents, may increase as much as the 5 th or 6 th power of the temperature.

7. The weakening effects in pressboard, and very likely other water-absorbent insulations, may also increase as much as the 5 th or 6 th power of the per cent absorbed moisture. When the free moisture is above 3 per cent the weakening effects due to its presence are quite pronounced.

8. Empirical equations are derived that will express the dielectric losses, currents, and power factors, as functions of the voltage, temperature, and absorbed moisture. 


\section{Discussion on "An Investigation of Dielectric Losses} with the Cathode Ray Tube" (Minton), Deer Park, Md., July 2, 1915.

H. W. Fisher and R. W. Atkinson: I believe the company with which the writers are associated was one of the first in this country to make extensive experiments relative to dielectric losses in cables and insulating materials.

After receiving valuable suggestions from the Bureau of Standards, special apparatus was designed for this work, which in connection with a vibration galvanometer was found to give very satisfactory results in determining dielectric losses, power factors, a-c. capacitance, etc. With this apparatus, varnished cambric manufactured by different companies was tested and power factors obtained at ordinary temperatures ranging between 4 and 20 per cent. A special apparatus was designed by means of which single thicknesses of insulating materials could be tested and also another apparatus in which the dielectric properties of insulating compounds could be determined. Later a Rowland dynamometer was adapted as a very sensitive wattmeter, for measuring energy losses at high voltages.

Experimental cables, made with varnished cambric of high dielectric loss, when subjected to excessive voltages, gradually became hotter and hotter until burn-outs occurred, whereas similar cables made with material of small dielectric loss and subjected to the same test, scarcely became warm.

Many different tests were made and the results carefully investigated in order to determine the best materials to use and the best methods of treatment of different dielectrics, etc. Some of the results of these tests have appeared in one or more papers presented by the authors at previous meetings of the A. I. E. E. A careful study of the results of all these experiments made on a great variety of materials manufactured or treated in different ways showed how dielectric losses can be reduced to a minimum, thereby insuring serviceable and efficient manufactured products.

Referring once more to the paper of the author, we find that the tests given were made on samples of varnished cloth and pressboard. As we have had no experience with the latter material, our comments will refer to tests of varnished cloth, dry paper as used in telephone cables, and saturated paper as used in electric light and power cables.

After carefully examining the results of the author's experiments on different samples of varnished cloth, we find that these are practically in agreement with tests made by us. The power factor of cables insulated with varnished cloth does not change appreciably with increase of voltage up to the operating voltage of the cable. As the voltages are increased above this point a slight increase in the power factor takes place, the rate of increase becoming greater as the voltage approaches the point of rupture.

We also find that the power factor increases with rise of 
temperature in somewhat the same way as shown by the author in Fig. 12. It should be borne in mind that in the case of varnished cloth, lower power factors can be obtained by the application of high temperatures for a long time, but such a treatment if carried to excess injures the mechanical properties of the cloth, thereby making the cables more liable to injury from bending during the process of installation.

We have found that the capacitance of varnished cloth cables does not appreciably change with voltage or temperature up to the point where a marked change occurs in the power factor. By the use of the term capacitance we mean the capacitance as measured by a-c. method and not that as usually measured by the discharge deflection galvanometer method. The apparent capacitance as measured by the latter method increases very rapidly with rise of temperature.

In the case of dry core telephone cables the percentage of moisture in the paper may very much affect the insulation resistance, and the apparent electrostatic capacity, and the temperature coefficients of these. A statement of the amount of moisture contained is somewhat arbitrary, because further moisture can always be eliminated from dry paper in any condition, until complete charring is reached. Our results on this material are, in general, similar to those given in Figs. 26 and 27 of the paper, except that any increase in moisture produces some increase in capacitance and in power factor. However, as shown in these curves, the effect upon these properties is very slight for a small amount of moisture and the effect is much less at low temperatures than at high. One half of one per cent moisture in the paper of any cable does not increase the apparent capacitance much above that of the same cable where the amount of moisture has been eliminated as far as possible without charring the paper. As the percentage of moisture becomes greater, the apparent capacitance increases at a greater and greater rate at ordinary temperatures, and becomes excessive at high temperatures. The true capacitance also increases with increase of moisture and temperature, but at a much less rate. The effect of moisture as shown in our tests on dry paper is also similar to the data given in Fig. 27, except that the power factor at low temperatures is lower for dry paper and there is no dip in the curve. We have, however, found, in tests made on many compounds, that there is a temperature at which the power factor is a minimum.

In the case of saturated-paper-insulated cables we have found that the power factor and capacitance vary with voltage and temperature in much the same way as already shown in the case of varnished cloth, the principal difference being that the power factor of paper-insulated cables at low temperatures is very much less than that of varnished cloth. Of course, the materials used and the method of treatment, both in the case of varnished cloth and of paper, very much affect the absolute 
value of the power factor, but without influencing the general characteristics just described. The general effect of moisture in saturated-paper-insulated cables is similar to that described by the author for treated pressboard.

We have found that dielectric loss in some few cases measured at low temperatures varies directly with frequency, whereas at high temperatures where the loss has been considerable, there is slight variation with frequency. These results were obtained from tests within the limits of 25 and 60 cycles.

The importance of dielectric loss lies in the fact that it produces heat and thus still further increases the temperature of the cables. This is most serious at high voltages, because for the same power factor, the energy loss is then so much greater. The Institute Standardization Rules take account of this by allowing different limiting temperatures for cables operating at different voltages.

A. S. McAllister: The author states that the loss varies with a power of the voltage ranging from 1.3 to 2.5. The loss should be expected to vary at some power of the voltage not less than 2. It is not improbable that the tests at higher voltages were made on materials physically different from those used in the tests at lower voltages, the change in the character of the material being brought about by the increased temperature. If as the temperature is increased the conductivity of the material decreases the loss will vary at a power of the voltage less than 2. If, however, the conductivity increases with increasing temperature, the loss will vary at a power of the voltage greater than 2. I should like to ask the author if the change in conductivity with change in temperature has any bearing on the cases reported by him.

John P. Minton: That point is explained in the paper.

W. I. Middleton and C. L. Dawes: Mr. Minton has, we believe, underrated the information obtainable from low-voltage d-c. measurements of the resistance and of the capacity of insulating materials. In connection with cables we have found in many cases that the insulation resistance drops materially after the insulation has been subjected to electrostatic stress, especially if the stress is carried near or to the breakdown point. We have found that the ability of the insulation to recover its initial resistance is a means of determining as to whether it has been permanently injured by over-stress or not. Certain high grades of insulation show no appreciable drop in insulation resistance after being subjected to high stress. These facts are borne out to a certain extent by Figs. 7 and 13 in the paper, where the total loss increases faster than the voltage squared. The hysteresis loss is of course included in the losses as shown in these figures.

We have further found that the d-c. capacity increases with stress and also if a high condition of stress is reached, the capacity may not return to its initial value. Similar results are shown by the author in Figs. 15 and 23 where the current increases 
faster than the voltage and also in the statement of conclusion 2 by Mr. Minton. These effects have a very important bearing upon cable testing, for by the insulation and capacity measurements, too severe testing of the insulation can be detected.

In Tables I and II are given data illustrative of these effects.

TABLE I-WIRES SHOWING RESULTS OF STRESS.

MEgOHMS IN $1000 \mathrm{FT}$.

\begin{tabular}{|c|c|c|r|r|r|r|r|r|}
\hline $\begin{array}{c}\text { Test } \\
\text { No. }\end{array}$ & Feet & $\begin{array}{c}\text { Before } \\
\text { volt- } \\
\text { age }\end{array}$ & $\begin{array}{c}2500 \\
\text { volts } \\
1 \text { min. }\end{array}$ & $\begin{array}{c}5000 \\
\text { volts } \\
1 \text { min. }\end{array}$ & $\begin{array}{c}\text { After } \\
2 \text { hr. }\end{array}$ & $\begin{array}{c}5000 \\
\text { volts } \\
5 \text { min. }\end{array}$ & $\begin{array}{l}\text { After } \\
2 \mathrm{hr} .\end{array}$ & \\
\hline 1 & 1562 & 14,500 & 14,500 & 7,500 & 11,500 & & & \\
2 & 1547 & 22,000 & 22,000 & 16,000 & 18,000 & & & \\
3 & 3150 & 7,500 & 7,500 & 6,000 & 7,000 & 5000 & 5000 & \\
4 & 1740 & 15,000 & 15,000 & 6,500 & 10,000 & 750 & 2500 & \\
5 \\
\hline
\end{tabular}

TABLE II-WIRES SHOWING RESULTS OF STRESS.

MICROFARADS PER 1000 FT.

\begin{tabular}{|c|c|c|}
\hline Feet & $\begin{array}{c}\text { Before volt- } \\
\text { age test }\end{array}$ & $\begin{array}{c}\text { After 5000 volts } \\
\text { for 1 min. }\end{array}$ \\
\hline 3150 & 0.126 & 0.130 \\
2176 & 0.146 & 0.150 \\
2470 & 0.130 & 0.134 \\
2925 & 0.130 & 0.133 \\
2775 & 0.120 & 0.124 \\
\hline
\end{tabular}

In impregnated paper cables, high insulation resistance and high dielectric strength rarely occur simultaneously. A high insulation resistance may mean a low degree of impregnation and consequently low dielectric strength. This is due not only to insufficiency of insulating compound, but to the fact that the dry paper is more or less brittle and becomes injured mechanically with handling. An increase in the amount of impregnating material may reduce the insulation resistance but increase the dielectric strength of the cable. Thus it can be seen that considerable information is obtainable from low-voltage measurements.

As a matter of interest to ourselves we have measured insulation losses upon commercial lengths of cable by means of a portable wattmeter. The current coil was connected in the ground lead going to the sheath and the voltage was stepped down by means of a potential transformer. The inductance 
of the potential coil of the instrument was made negligible by connecting a high non-inductive resistance in series with it. Although we did not know the phase angle of this particular potential transformer, the maximum error from this source, computed from the phase angles of similar transformers, did not exceed 5 per cent. We soon expect to be in a position to check these results by another method. Of course, this method would not be applicable to the small samples tested by Mr. Minton.

F. W. Peek, Jr.: Mr. Minton's paper shows clearly the great importance of thoroughly drying and removing occluded air from insulations before putting them into apparatus; the importance of operating at moderate temperature; and the necessity of keeping apparatus free from moisture. The chief use of loss measurements in practise is to check the condition of the insulation before it is put into use.

It may be of interest to compare the mechanism of loss in gaseous, liquid and solid insulations.*

In oil, and particularly in air, there is very little loss until local breakdown is reached. The loss in brush discharge or corona then increases directly as the square of the excess voltage above the critical voltage. With solid insulations, loss appears as soon as voltage is applied. The loss may be due to:

(1) The so-called dielectric hysteresis or lag of the flux behind the e. m. f. due to some molecular action.

(2) The loss due to conduction. Practically all solid insulations absorb moisture to a greater or less extent. The capillary

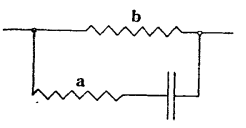

FIG. 1 tubes and microscopic interstices, etc., in the structure become filled with moisture and gases. In the non-homogeneous structure this makes a complicated arrangement of capacities and resistances in series and in multiple, as shown diagrammatically in Fig. 1.

The losses due to (1) should vary as the square of the voltage and approximately as the frequency.

$$
p_{1} \cong a_{1} f e^{2}
$$

The losses due to (2), Fig. 1, $a$, vary as the square of the voltage and approximately as the square of the frequency when the resistance is small and constant.

Thus

$$
p_{2} \cong a_{2} f^{2} e^{2}
$$

The loss due to (2), Fig. 1, $b$, must vary as the square of the voltage, if the resistance remains constant, but is independent of the frequency.

$$
p_{3}=a_{3} e^{2}
$$

The total loss may then be made up of a number of components, thus:

$$
p=p_{1}+p_{2}+p_{3}=a_{1} e^{2} f+a_{2} e^{2} f^{2}+a_{3} e^{2}
$$

*For more extensive data, etc., see Chap. VII, "Dielectric, Phenomena in High-Voltage Engineering". 
In poor insulation, or in insulation containing moisture, the loss may increase at a greater rate than the square of the voltage, as the resistance will decrease with increasing voltage.

In homogeneous insulations in good condition the last two terms are small and the expression for loss becomes

$$
p=a e^{2} f
$$

and for certain insulations

$$
p=a e^{2}(f+c)
$$

I believe that the deviations from the square law in $\mathrm{Mr}$. Minton's paper are due to the conditions of the insulation. From examination of a considerable number of experimental data obtained by myself and others I have found that

$$
p=a e^{2} f
$$

is generally followed, or, putting this in the gradient, $g \mathrm{kv} . / \mathrm{mm}$., in place of $e$,

$$
p=b g^{2} f 10^{-6} \text { watts per cu. cm. }
$$

At 25 deg. cent. $b$ is

2 to 15 for oiled pressboard-depending upon the quality or kind. 5 for glass. 7 to 10 for varnished cambric.

The values for varnished cambric were obtained for 60 cycles and 40,000 to 100,000 cycles. The values at the high frequencies were calculated from measurements made by Mr. Alexanderson.* These values follow very closely the square law.

The loss and, therefore, $b$, increases approximately with increasing temperature in the form

$$
b=K t^{n}
$$

where $t$ is the absolute temperature in deg. cent.

For varnished cambric

or

$$
b \cong 1.2 t^{10} 10^{-26}
$$

$$
p=1.2 g^{2} t^{10} 10^{-32} \text { watts } / \mathrm{cu} . \mathrm{cm} \text {. }
$$

*Proceedings Radio Engineers, June, 1914.

"Dielectric Phenomena in High-Voltage Engineering", pages 185-187. 
In some cases for insulations like varnished cambric I have noted that the equation sometimes takes the form

$$
p=b g^{2}(f+c)
$$

Charles L. Fortescue: Mr. Minton's paper is an example of the tendency to consider the problem of insulation in a scientific spirit. It is only in recent years that it has dawned on the minds of engineers that the problem of insulation is a subject that is capable of scientific treatment, and that good results will be obtained by considering it in this spirit. I may say that Dr. Ryan mentioned today an example of applying a simple principle of insulation to the problem of insulating apparatus for highvoltage testing, and he informed me that he had a great deal of trouble before applying this principle, but that after he had applied it he had no further trouble. It is necessary, however, in order to take full advantage of insulating materials, to determine their dielectric properties, and this is what Mr. Minton is showing us how to do. There are other methods of measuring the losses in insulation that are equally as good as far as commercial results go, but the advantage of this particular method seems to me to lie in the fact that it presents us with a graphic record of the test in the form of a Lissajous figure which may be an ellipse or something else. It occurred to me that we could obtain the analysis of current and e.m.f. from the Lissajous figure by applying a method similar to those which $\mathrm{Mr}$. Chubb has brought out in some articles recently in the electrical journals, and an actual analysis of the operation of the dielectric could then be obtained.

By the method outlined in the paper we are enabled to determine whether any changes take place in the dielectric properties of the material during the cycle, which is a very important point. On account of its lack of inertia, the cyclograph may be used to determine the action of dielectric materials at very high frequencies, which, in connection with the effect of distorted waves on insulation, is a subject which has been given but very little consideration. It is very interesting to note that the dielectric losses may be expressed in terms of moisture and temperature by a very simple equation.

Mr. McAllister brought up the point that in his opinion the dielectric loss should be proportional to the square of the voltage. I do not think there is any reason for this assumption. The dielectric loss will not depend upon resistance in the true sense. When we talk of the a-c. resistance in the dielectric, we are simply using an expression based on the voltage component in phase with the current, and the actual loss may consist of a molecular loss which is due, one might say, to the polarization or displacement in the molecule itself, that is, to a change in the configuration of the electrons, but there is no reason to suppose that the loss due to any change in configuration is directly proportional to the square of the voltage. 
W. C. Arsem: The subject of dielectric loss is assuming more importance as engineers are beginning to recognize its bearing on the quality of insulating materials. It is now realized that many failures of insulation are due to the cumulative effects of dielectric loss. If insulation be used under conditions such that the rate of dielectric loss, as heat, is greater than the rate of dissipation of heat by conduction and radiation, the temperature will rise. But the dielectric loss increases with rise of temperature, so that the insulation keeps getting hotter until it is melted, charred or punctured.

Mr. Minton is to be congratulated upon having perfected an apparatus by which a full set of measurements may be made in a short time. I hope full advantage will be taken of this apparatus and method to secure some accurate data on dielectric losses in pure and easily reproducible materials, such as mica, glass and oils at different frequencies, voltages and temperatures, and also different thicknesses of insulation. Such data would help to establish some theory of dielectric loss which would correlate all known phenomena and facilitate the improvement of insulating materials.

The theories that have been proposed to account for the properties of imperfect dielectrics fall into three general classes: First, the inhomogeneity theory of Maxwell, according to which an imperfect dielectric is assumed to be made up of portions having different dielectric constants and specific resistances. Second, the hysteresis theory which is based on the view that the dielectric displacement is not determined by the instantaneous value of the applied potential, but depends upon the previous history of the dielectric. The behavior of an imperfect dielectric in an electric field is not exactly analogous to that of iron in a magnetic field, for in a dielectric the final value of the displacement remains proportional to the potential, except that there is a time-lag. The loss per cycle in a dielectric, moreover, depends on the length of the cycle. A theory of viscous hysteresis has been developed by Pellat, in France, and von Schweidler, in Austria, which has been applied with some success in special cases.

The third theory advanced is the ionic theory. It assumes that in a perfect dielectric there is no conductivity in the ordinary sense, but only a practically instantaneous displacement of one or more electrons in each molecule when a potential difference is applied. In an imperfect dielectric, however, there are also ions of molecular dimensions resulting from the dissociation of the dielectric itself or impurities. These ions are responsible for residual charges, dielectric losses and the apparent variation of the dielectric constant with frequency.

The ionic theory is rapidly gaining favor, and to my mind is the most likely to prove correct.

In reference to Mr. Peek's remarks, just before his closing, it might be supposed from what he said, that it had been established that the loss depends upon the frequency and is in exact 
proportion to it, but I do not believe that any results have been obtained yet which prove it conclusively. In fact, some data which have been obtained very recently in research work show that the relation is not linear. The ionic theory would indicate quite a different relation.

H. J. Ryan: The cathode ray tube has two familiar traits that are virtually its own: (1) Tracing cyclograms that furnish wave forms, cyclic energies, and power factors. (2) Condensers are employed exclusively for the voltage and current controls. In most work these control condensers are comparatively inexpensive and free of frequency and resistance errors. The tubes may, therefore, be used for indicating values at high voltages and sustained high frequencies, or at the highest frequencies in steadily recurring transients. By these two traits the cyclograph offers special advantages for the measurement of small powers applied at high voltages over the widest range of frequency. It has been found quite feasible and convenient to use the cyclograph without changing any of its adjustments to measure the voltage, current and power factor employed in corona formation about the same conductor at 60 and again at 180,000 cycles.

When we began to use high-frequency sources for experimental work and study, in our laboratory, we were distressed to find that it was difficult to provide insulating supports for the main electrodes carrying voltages of 50,000 and more. The conductors, a half inch in diameter and more, delivering such voltages, when supported on glass rods, glass or porcelain insulators or insulators of the usual refractory materials that might be employed, would cause such insulators to crack and fall to pieces. For the time being, cotton threads were the only enduring insulators and these conductors were thereby supported. That, of course, was very unsatisfactory. Then it occurred to us that the Fortescue-Farnsworth principle brought out beautifully in their paper and a demonstration of which I had witnessed in Mr. Fortescue's laboratory with high voltages at 60 cycles, was even more available at these higher cycles. By this principle, we eliminated the atmosphere that causes over-stresses, substituting all such atmosphere with solid dielectric. By the use of this principle every source of trouble in supporting conductors carrying high voltages at sustained high frequency completely disappeared. There should be no great difficulty in providing insulators for delivering, in so far as there will be occasion to deliver, the higher voltages at the higher frequencies.

R. P. Jackson (by letter): Mr. Minton's paper verifies similar data obtained in an entirely different way. Fig. 21 gives curves of power factor of oil-treated pressboard at different temperatures and voltages. The rise of power factor with temperature is perfectly natural, and is generally characteristic of most insulation. The falling of power factor with rise of voltage, however, is not characteristic of all insulation and is 
a feature which was hard to believe when betrayed by our own investigations. For that reason, the data were taken over several times to verify the fact. The results remained the same, however, and the next problem is to find an explanation. In general, insulation having leakage has something of a coherer characteristic which causes apparent drop of resistance with rise of voltage, with consequent increase of losses more rapidly than the square of the voltage. Insulation having losses rising more rapidly than the square of the voltage, therefore, has a normal and readily explained loss and power factor curve. When the losses rise less rapidly than the square of the voltage and with a falling power factor with rise of voltage, there is evidently some polarizing element which is difficult to explain. Incidentally, this feature is highly desirable in insulation. We should like to know if any physical or chemical explanation has been offered, covering this feature.

H. W. Fisher: In the discussion by Professor Dawes and Doctor Middleton, the statement is made that in testing certain cables there was a great difference in the insulation resistance before and after the high-voltage test. I would like to ask Mr. Dawes what kind of insulation was used in the cables tested. We are meeting specifications which require that the insulation resistance before and after the voltage test shall differ by only a small amount. In wires insulated with certain kinds of material there might be a change in the insulation resistance before and after the voltage test, but in the case of saturatedpaper-insulated cables, when tested at from two and a half to three times the working pressure, the insulation resistance test made after the application of high voltage would be practically the same as that made before, provided the temperature of the cable has not changed during the application of high voltage. This may occur if the high-voltage test lasts for half an hour.

Chester L. Dawes and W. I. Middleton: In each of the instances cited the insulations were thirty per cent rubber compounds. The insulations that show such decided drops in resistance were low-voltage compounds not designed for the voltages to which they were -subjected. Consequently, they were overstressed. On the other hand, the insulations which showed little or no drop in resistance were made of our hightension compounds, designed to withstand high voltages without becoming overstressed. Both contain the same proportion of Para rubber (30 per cent), but the different characteristics are due entirely to the proportionate amounts of mineral ingredients added.

Clayton H. Sharp: It seems to me it is very important, for the general utilization of the details Mr. Minton has developed, to have certain means of exciting the tubes. Mr. Minton refers to a number of means in his paper. I think if we could hear a little more of the most practical way of doing it that it might be interesting. 
C. W. Davis: The loss of energy in the dielectric is, as Mr. Minton has said, an exceedingly important matter and knowledge of it is necessary for the proper use of insulating materials. There are so many factors entering into the problem of.insulation that this particular factor, viz., energy loss, may, and sometimes does, receive undue weight. Enough is known of insulating materials at the present time to permit of the selection of insulating materials of low energy loss which are more or less suitable for any given purpose. To find the material that is exactly suitable is a different problem and the material which is exactly suitable under one set of conditions is anything but suitable under another. It is doubtful if there is any one material that will answer in the fullest degree all of the requirements, even in a relatively limited field of manufacture such as high-voltage cables. A cable that is laid in winter has very different demands upon the insulation than one laid in summer. A cable required for operation in very hot ducts will have to operate on a different portion of the temperature-energy loss curve than a cable laid under water. Material of relatively high energy loss may at times be the only logical selection where some other desirable physical characteristic becomes the controlling factor.

It is not obvious from reading the description of the improved form of Professor Ryan's power-factor indicator and the method of using it, why Mr. Minton should have preferred this method to that of the electrostatic wattmeter. To be sure, the latter is more or less troublesome to handle. However, it would appear to require much less space than the apparatus here described. An additional advantage of the electrometer is that it is direct reading. It is possible to build electrostatic instruments for measuring small losses in insulating materials which with air insulation at atmospheric pressure can be used in measurements up to 20,000 volts. With compressed air or gas as suggested by Rayner, and used by Tschernyschoff (E.T.Z. June 4, 1914, page 656), or with oil insulation, the measurements may be made at much greater voltages. Even low-voltage electrometers may be used with air condensers as potential dividers and while more troublesome are perhaps justifiable where more accurate results are desired. Besides, it would seem possible by superimposing an electric field upon the moving element, in the manner used by Fortescue* in the condenser terminal, to so largely reduce the stress at the edge of the needle as to overcome the difficulty from corona, though the consequent loss of pull on the needle would have to be compensated for by largely increased sensitivity.

Bridge methods have also been used with success up to 10,000 or 20,000 volts. Monash (Annalen der Physik, Vol. 22, 1907, page 905), succeeded in using a series bridge method successfully up to 12,000 volts. But the difficulties met with by Monash at high voltages are very considerably reduced in other bridge arrangements.

In the laboratories of the company with which the writer is

* Trans. A. I. E. E. 1913, Vol. XXXII, Part I, p. 893. 
connected we have made use of bridge methods for examining insulating materials for a number of years past (TRANs. A. I. E. E., 1907, Vol. XXVI, Part II, page 997), and more recently have made use of the Rowland dynamometer up to 100,000 volts and the electrostatic wattmeter up to 20,000 volts for measurements of the same general type as described by Mr. Minton.

The peculiar behavior of insulating material such as that noted in Fig. 21 of Mr. Minton's paper has been noted by us with oilimpregnated paper in one or two instances. The falling off of power factor with increased stress, however, is much less marked than with the material here referred to. The decrease of power factor with increasing stress was, however, as in Fig. 21, more marked at high temperatures than at low temperatures. So exceptional were these results that we have felt inclined to suspend judgment as to their credibility until we received further evidence. Mr. Minton's confirmatory results are therefore of much interest to us.

John P. Minton: In regard to Messrs. Fisher and Atkinson's discussion, they have taken up a number of examples that I intended to give, but neglected to do so on account of the length of the paper and the amount of material I had to present. I am glad, however, that these things have been brought up in connection with this discussion. They refer to the amount of moisture that an insulator contains, and I believe say that the results are more or less arbitrary, depending on the actual moisture present. The moisture I have dealt with in the paper is free moisture and not combined. You can eliminate the combined moisture by heating to a sufficiently high temperature to cause charring effects. That part of the moisture I have not considered at all, simply the free moisture which exists in the insulation, and which was determined with sufficient accuracy as described in the paper. Messrs. Fisher and Atkinson also referred to some results they had at 30 and 60 cycles. Results I have taken from 30 to 420 cycles show some very interesting facts. Later I hope to be able to publish some of these results.

Mr. Dawes said that I apparently underestimated the importance of steady potential effects. These effects I have not gone into in the paper, because the a-c. phenomena are far in excess of any d-c. effects that I noticed. I do not wish anybody to think we have underestimated anything whatever, because my experience has taught me not to underestimate any phenomena until they have been subjected to test.

Mr. Peek referred to the mechanism of dielectric conduction, the effects of frequency, and breakdown voltage, etc. These effects I have gone into, but on account of the length of the paper I left them out, hoping some one else would bring them up. The results that I have, showing the influence of frequency, however, will bring out certain effects which Mr. Peek spoke of as to the combination of capacities and resistances, and will also bring out the effect to which Mr. Dawes referred. 
Mr. Fortescue inquired about the deflection being directly proportional to the voltage for the current deflection. He

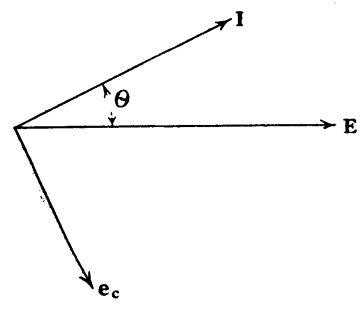

Fig. 2 speaks of it as a velocity deflection. That is what Mr. Ryan referred to in his first paper in 1911. What I have called the current condensers he called velocity condensers. The way that ${ }^{\circ}$ comes about is this. Referring to Fig. 2, herewith, the instantaneous voltage, $e$, applied to the system is $e$ $=E \sin \omega t$. The instantaneous current passing through the current condensers is $i=I \sin (\omega t+\theta)$. Now

$\frac{d i}{d t}=I \omega \cos (\omega t+\theta)$, and the voltage, $e_{c}$, across the air

current condensers is proportional to and in phase with this rate of change $i$. The deflection of the cathode ray stream is equal to some constant multiplied by $e_{c}$ or by $\frac{d i}{d t}$. For this reason Prof. Ryan has called velocity deflection and velocity condensers what I have called current deflection and current condensers.

He also refers to the square law as not necessarily something to be accepted. I have referred to that in my paper, and have taken it up quite fully, so that anybody should be able to appreciate the conditions under which we are working. It is not necessary, then, to explain that any more.

Mr. Arsem suggested the necessity of getting data on pure materials, with different thicknesses, and has also referred to the various theories that have been proposed. These theories I do not wish to consider at this time, because I do not wish to suggest any theory until I have a sufficient amount of data on which to base it. The results on pure materials are very necessary, but for the present the manufacturers and engineers desire results on actual materials used.

I do not think it is necessary to amplify or make any remarks in connection with Prof. Ryan's statements. I appreciate all of them even more than most people do.

Dr. Sharp has asked about the most practical way of exciting the tubes. The most practical way, so far as I know, is the method I have been using. This is a mechanical commutator which rectifies the peaks of the waves. I have used the commutator up to 30,000 volts - it is a small commutator made of fiber, with short brass segments at four equal points on the perimeter. That has not given me any trouble whatsoever, and it takes only a few seconds to start the tube. It is a simple and a convenient thing to use. I look favorably upon the kenotron developed by Dr. Dushman, but I have not had a 
sufficient amount of experience with it to recommend it. There are other methods of exciting the tubes, but there are none of them which I consider as practicable as the mechanical commutator or the kenotron. Personally I prefer the mechanical commutator to all the others.

Several of the speakers have referred to the use of the dynamometer and the electrostatic wattmeter for measuring dielectric losses in insulation. It would seem that some of them cannot understand why the cyclograph method should have been preferred to these other two methods. For this reason some further remarks seem to be necessary. With regard to the ordinary electrostatic wattmeter, it may be stated that its use is out of the question for this work, for we wish to make measurements up to 200,000 volts or more. Furthermore, the method is not free from frequency errors, and reliable results cannot be obtained at the high frequencies. If oil insulation is used the greatest care must be exercised to prevent the oil from becoming unreliable through absorption of moisture or becoming mixed with other harmful foreign matter. It is difficult for me to feel certain of the accuracy of the results if any insulation other than air is used for work of this nature. With air one does not encounter frequency and resistance errors. With regard to the dynamometer, I may say this instrument has been in use in the Pittsfield laboratory for some time. I have made check measurements with the dynamometer and the cyclograph, and the agreement is satisfactory, being within a few per cent. It is necessary to make the check runs on test samples under exactly the same conditions. The dynamometer, however, is far from being satisfactory for low power factors, and cannot be used for measurements with anything but the ordinary frequencies, such as 60 cycles. It does not read direct and requires frequent calibration. It is no more convenient to operate than the cyclograph. If one wishes to make measurements up to very high voltages $(200,000$ to 500,000 volts) and at various frequencies up to say $10^{6}$ cycles per second, he could hardly expect to make use of any apparatus other than the cyclograph. Since a study of insulation when subjected to high-frequency potentials is becoming of much importance, it is well to have apparatus such as the cyclograph to make use of.

Another important factor is the study of the effects in insulation produced by waves of various shapes, as well as the distortion in wave shape produced by the insulation itself. The graphic method of the cyclograph fulfills this requirement nicely. For these and other reasons I have preferred to use this apparatus in the work along the lines laid down in the present paper.

There has been no criticism of the results I have given. Everyone seems to be satisfied with the accuracy of them, and with the information which this method allows us to obtain. 